\title{
On-machine and in-process surface metrology for precision manufacturing
}

\author{
W. Gao (1) ${ }^{\mathrm{a}, *}$, H. Haitjema (1) ${ }^{\mathrm{b}}$, F.Z. Fang $(1)^{\mathrm{c}, \mathrm{d}}$, R.K. Leach $(2)^{\mathrm{e}}$, C.F. Cheung $(2)^{\mathrm{f}}$, E. Savio (1) ${ }^{\mathrm{g}}$, \\ J.M. Linares $(1)^{\mathrm{h}}$
}

a Tohoku University, Japan

${ }^{\mathrm{b}}$ KU Leuven, Belgium

c Tianjin University, China

${ }^{\mathrm{d}}$ University College Dublin, Ireland

e University of Nottingham, UK

${ }^{\mathrm{f}}$ The Hong Kong Polytechnic University, Hong Kong

${ }^{\mathrm{g}}$ University of Padova, Italy

${ }^{\mathrm{h}}$ Aix-Marseille Université, France

\section{A R T I C L E I N F O}

\section{Keywords:}

Surface

Metrology

Manufacturing

\begin{abstract}
A B S T R A C T
On-machine and in-process surface metrology are important for quality control in manufacturing of precision surfaces. The classifications, requirements and tasks of on-machine and in-process surface metrology are addressed. The state-of-the-art on-machine and in-process measurement systems and sensor technologies are presented. Error separation algorithms for removing machine tool errors, which is specially required in on-machine and in-process surface metrology, are overviewed, followed by a discussion on calibration and traceability. Advanced techniques on sampling strategies, measurement systems-machine tools interface, data flow and analysis as well as feedbacks for compensation manufacturing are then demonstrated. Future challenges and developing trends are also discussed.

(C) 2019 CIRP. Published by Elsevier Ltd. All rights reserved.
\end{abstract}

\section{Introduction}

As an important discipline of manufacturing metrology, surface metrology is defined by Whitehouse as the measurement of the deviations of a workpiece from its intended shape specified in the design drawing [241]. Surface metrology includes the measurement of surface texture and surface form errors, specified, for example, by roundness, straightness, together defined here as surface topography [136]. Since the function and performance of a workpiece, as an element in a machine or a mechanical system, are strongly influenced by its surface topography, surface metrology is an essential operation in manufacturing of the workpiece. Both the instrumentation and characterization technologies of surface metrology have been well established over the long history of manufacturing. A large variety of commercially-available surface measuring instruments, from the mechanical stylus profilers [240] to the noncontact optical instruments [94,132] to scanning probe microscopes [33], can be selected to examine the surface of a workpiece for acquiring cross-sectional profile or areal topography data of the surface. Software associated with the instruments or stand-alone software packages can be employed to calculate the surface parameters defined by international standards for quantitative characterization of the surface $[36,111]$. A calibration and

\footnotetext{
* Corresponding author.

E-mail address: gaowei@cc.mech.tohoku.ac.jp (W. Gao).
}

verification infrastructure has also been developed to support surface metrology [134], although the relevant international standards are still under development. In addition, surface metrology has been expanded to cover complex surfaces, such as structured surfaces [45] and freeform surfaces [56,195].

Surface metrology is an important part of post-manufacturing inspection of a manufactured workpiece, which is typically carried out in an environmentally well-controlled metrology room, to determine whether the surface parameters of the workpiece meet the designed requirements for the purpose of quality control of the workpiece. On the other hand, as stated by McKeown, the maximum efficiency of quality control occurs when the measurement is carried out at the closest possible point to the manufacturing process, e.g. on-machine and in-process surface metrology [164]. This kind of practice has long been observed in precision manufacturing of telescope mirrors, due to the tight tolerances of surface parameters and the large mirror size $[35,84,211]$. For instance, the process chain of manufacturing a $4.2 \mathrm{~m}$ off-axis aspheric telescope mirror was composed of casting, generating, grinding, polishing and figuring process stages [182]. Different measuring instruments, including laser trackers, IR and visible deflectometry and computer generated hologram (CGH) null interferometry were employed to acquire the surface form error data at different stages of the process chain. Meanwhile, the surface waviness and roughness data were acquired by subaperture deflectometry and temporal phase-shifting interferometry, respectively, in the polishing and figuring stages. The 
measurement data were employed in the compensation machining to ensure that the mirror surface satisfies the required form and roughness tolerances.

In addition to quality control of workpieces, on-machine and inprocess surface metrology are also effective for control of manufacture through optimizing the manufacturing process and the machine tool settings, based on the fact that the surface texture is representative of the process characteristics and the surface form errors are footprints of the machine tool imperfections; i.e. vibration, geometric error motions and thermal distortion [111,241]. It is becoming more feasible to implement surface metrology on the machine tool and in the manufacturing process with improvements in the stability of the machine tool [80]. In recent years, on-machine and in-process surface metrology is playing an increasingly important role in the process chain of traditional manufacturing that is composed of cutting, grinding and polishing for precision workpieces with complex shapes and/ or extremely tight tolerances, such as freeform optics in head-up displays, large roll moulds for roll-to-roll replication and turbine blades of airplanes $[27,108,220]$. Similar trends are observed in the non-traditional manufacturing processes, such as additive manufacturing [199] and nano-scale manufacturing [54,55].

The classifications, tasks, and requirements of on-machine and in-process surface metrology for precision manufacturing, as well as the associated measuring instruments and sensor technologies, are presented in this paper, as a complement to the past CIRP keynote papers on measurement of surfaces. Error separation algorithms for compensation of kinematic or dynamic errors of the machine tools are overviewed, followed by a discussion on the issues of calibration and traceability. The data flow in the manufacturing and measurement system, from both software and hardware points of view, will then be reviewed. It should be noted that the measurement of dimensions and surface integrity, although both important aspects dominating the function of workpiece surfaces, will not be covered in this paper. Since inprocess is the ideal case of on-machine condition, it is treated as an independent term in the title of the paper to emphasize the importance of in-process surface metrology.

\section{General issues}

\subsection{Classifications}

In addition to "on-machine" and "in-process", the terms "insitu" and "in-line/on-line" are frequently used to describe the condition of a measurement activity, not limited to measurement of workpiece surface, in manufacturing metrology. However, there are no clear classifications for these terms. This can often lead to confusion and misunderstanding when specifying a manufacturing metrology activity. For example, "in-situ" is used as synonymous of "on-machine" and "in-process" in some manufacturing papers. One of the motivations of this paper is thus to classify these terms as shown in Fig. 1, so that they can be used distinguishably and properly in CIRP and in the manufacturing engineering community.

A workpiece is typically manufactured from the raw material to the final product by a manufacturing chain composed of a number

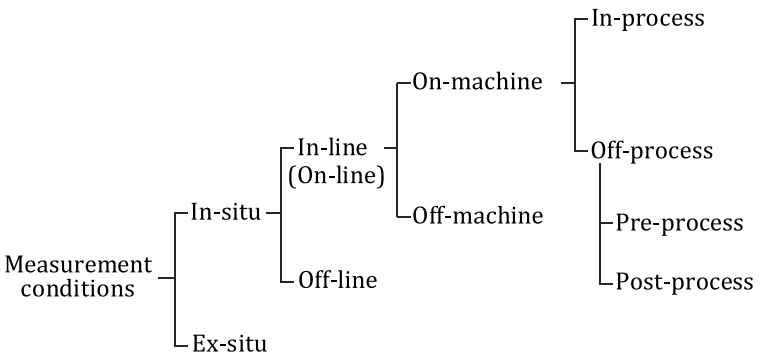

Fig. 1. Conditions of surface metrology for precision manufacturing. of fundamental manufacturing processes, such as casting, forming, turning, grinding and polishing. Each fundamental process is carried out by using a manufacturing machine. It should be noted that a machining activity can be iterative where the same fundamental process is repeated for a couple of cycles on the same machine, e.g. for compensation machining. In this paper, the term "process" is referred to the fundamental process instead of the entire process chain or the iterative process cycles for avoiding any possible ambiguity in the classification.

As illustrated in Fig. 2, the machines are arranged in a production line based on the process chain of manufacturing in a factory where the environmental conditions, such as temperature, vibration and humidity, may not be strictly controlled. On the other hand, surface measuring instruments are located in different places in the factory for measurement of the workpiece. In many factories, there is a metrology room that is environmentally isolated from the factory floor for a better controlled environment of measurement. The measuring instruments can then be categorized into two groups from the point of view of environmental condition: those that are placed in the metrology room and those that are not. The measurement of the workpiece surface carried out in the metrology room can be classified as "ex-situ" surface metrology, since the measurement environment is different from the manufacturing environment. Meanwhile, the corresponding "in-situ" surface metrology can be referred to as:

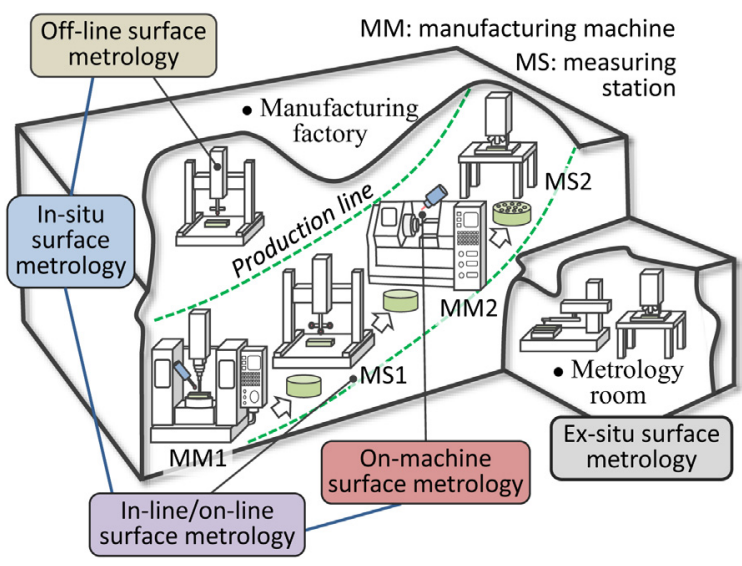

Fig. 2. Schematic of surface metrology in a factory with a production line

- In-situ surface metrology: measurement of the workpiece surface is carried out on the same work floor and in the same manufacturing environment, without isolating the workpiece from the manufacturing environment.

Measuring instruments outside the metrology room can also be categorized into two groups in terms of their locations with respect to the production line. Some of them are placed outside the production line. It is necessary to move the workpiece out of the line for the measurement of its surface by one or more of the instruments then return back to the line for further manufacturing when necessary. Such a measurement can be classified as "off-line" surface metrology. Meanwhile, the corresponding "in-line" or "online" surface metrology can be referred to as:

- In-line/On-line surface metrology: measurement of the workpiece surface carried out on a production line without moving the workpiece outside the production line.

When looking at the surface metrology carried out in the production line, the workpiece can either be measured when it is mounted on the machine or when it is moved out of the machine. The latter can be classified as "off-machine" surface metrology and the former can be classified and referred to as: 
- On-machine surface metrology: measurement of the workpiece surface carried out on a manufacturing machine where the workpiece is manufactured.

It should be noted that the above classifications have been made based on where the surface measurement of the workpiece is carried out. On the other hand, for on-machine surface metrology, since the measurement is carried out on the manufacturing machine, it is necessary to identify it with respect to the manufacturing process that is implemented on the same machine. As shown in Fig. 3, on-machine surface metrology can be conducted before the manufacturing process, which can be classified as "pre-process" on-machine surface metrology. It can also be conducted after the manufacturing process, which can be classified as "post-process" on-machine surface metrology. These two can be grouped as "off-process" on-machine or simply "offprocess" surface metrology. The corresponding "in-process" surface metrology, which is classified as another subcategory of on-machine surface metrology, can then be referred to as:

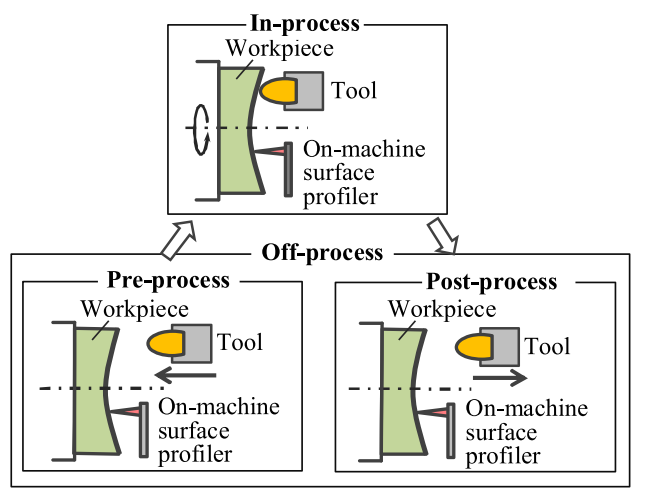

Fig. 3. Classifications in on-machine surface metrology.

\section{- In-process surface metrology: the on-machine measurement of workpiece surface carried out while the manufacturing process is taking place.}

Surface metrology carried out in the on-machine condition will be included in this paper. Although in-process belongs to the onmachine condition, it is treated as an independent term to emphasize the importance of in-process surface metrology, since it is the ideal case of on-machine surface metrology.

It should be noted that the above terms are employed to describe the measurement conditions in not only the fields of manufacturing and production engineering but also other fields of science and technology. The terms "in-situ" and "in-line/on-line" are used in a large number of fields, most popular in physics, chemistry, materials science and optics. On the other hand, the terms "on-machine" and "in-process" are most recognized in the fields of manufacturing and production engineering, which are the targeted fields for this keynote paper.

\subsection{Tasks and requirements}

Fig. 4 is a schematic of an on-machine surface metrology system. The most straightforward task of on-machine surface metrology is to replace conventional post-manufacturing inspection of the workpiece surface made on a stand-alone surface measuring instrument. Since on-machine inspection is made soon after the manufacturing process, and without moving the workpiece from the machine, the time interval from the end of the manufacturing process to the start of the inspection can be shortened to improve the inspection efficiency. The first step for this task is to integrate the surface measuring instrument with the machine tool; typically to mount the instrument on the machine tool. Taking into consideration the limited space of the machine tool and the accessibility of the workpiece surface, the measuring instrument usually needs to be compact. Moreover, it is often difficult to mount a complete commercial stand-alone measuring instrument, either full-field or probe-scan (see definitions in Section 3); rather only a part of the instrument can be mounted on the machine tool. The slide, spindle and numerical control (NC) controller of the machine tool then become important elements of the measurement system for on-machine surface metrology. For a probe-scan surface profiler, usually only the height $(Z)$ sensor of the instrument is mounted and the scan motion with respect to the workpiece surface in the XY-plane is provided by the slide and spindle of the machine tool. It is thus required to make use of the position data of the slide and spindle from the NC controller of the machine, or directly from the output of the rotary and linear encoders of the spindle and the slide, for constructing the topography data of the workpiece surface. Before mapping the workpiece surface, there is a necessary step to identify the position of the sensor within the machine tool coordinate system. An artefact or a workpiece with a known shape and a known position in the machine tool coordinate system is required for this purpose. It is also required to establish specific sampling strategies for probe-scan measurement systems based on the machine tool configuration and the shape of the workpiece.

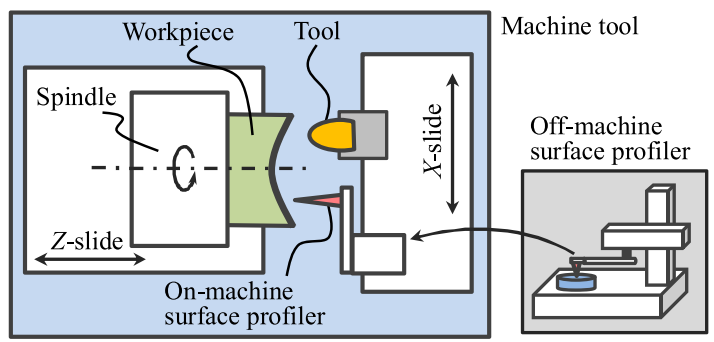

Fig. 4. Schematic example of an on-machine surface metrology system.

On-machine inspection can be carried out simultaneously with the machining operation, which is referred to as in-process inspection. Since no additional time is taken for the inspection, the maximum inspection efficiency can be obtained. In this case, the sensor head is required to be robust enough to the potentially severe machining environment, which is typically associated with machining fluid, produced chips, vibration and high temperatures. The measurement speed of the sensor head is required to be high enough so that it can follow the machining operation. The physical interference of the sensor head with the machining tool must be prevented. These requirements make in-process inspection of the workpiece surface difficult.

A significant difference between on-machine surface metrology and off-machine measurement by using a stand-alone surface measuring instrument is the resulting machine tool errors, including spindle/slide motion errors, thermal deformations and vibration. The alignment error of the sensor head on the machine tool is also an additional error source. Reduction and separation of such errors from the on-machine surface measurement results, as well as the related calibration and traceability issues, must also be considered.

Another task of on-machine surface metrology is for compensation machining (Fig. 5). The surface measurement data are fed back to the NC controller with a modified tool path, so that the deviations, i.e. the machining errors of the workpiece surface from the designed nominal shape, can be reduced. The surface metrology for this task can be carried out post-process or more ideally in-process. In either case, it is required to transfer the measurement data into the machine tool coordinate system and then make a comparison with the designed shape. If the designed shape is not provided by a set of discrete data but by a CAD model, modelling of the measurement data is then required to match with the CAD model so that the machining errors can be identified for compensation machining. Additional work on interfaces with the 
NC controller, from the point of view of both hardware and software, is thus required for compensation machining. On the other hand, the in-process surface metrology for this task is also subject to the same requirements for the on-machine inspection discussed above.

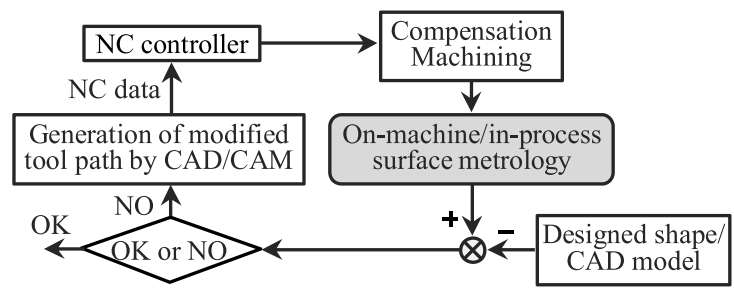

Fig. 5. On-machine surface metrology for compensation machining.

Since a manufacturing process is basically started from an initial workpiece alignment, this is often the first task of onmachine surface metrology. As discussed above, the surface of a workpiece is generated in a process chain composed of multiple manufacturing processes. The workpiece is machined to a certain shape in one process and is then machined to a modified shape in the next process, where modifications must be made based on the previous shape. The first operation for the next process is thus to align or to locate the workpiece accurately in the coordinate system of the corresponding machine tool so that the consequent machining can be accurately carried out over the existing shape. This can be realized by positioning the workpiece on the machine tool by "pre-process" on-machine surface metrology (Fig. 6). For this task, the coordinate system for the on-machine surface metrology is required to be consistent with that of the machine tool. The measurement is required to have enough resolution and accuracy in both vertical and lateral directions so that precision positioning of the workpiece is possible.

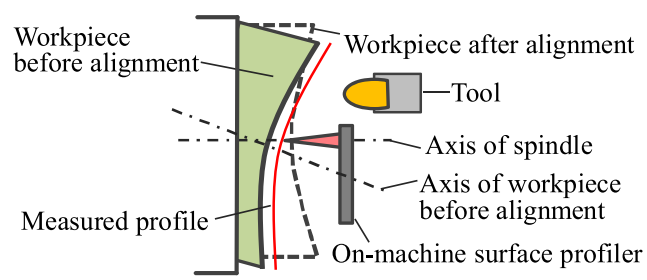

Fig. 6. On-machine surface metrology for initial alignment of workpiece.

Diagnosis of the manufacturing process and the machine tool is also a task of on-machine surface metrology. For each stage in the process chain, the workpiece surface is machined by a specific material removal or additive mechanism. A specific topography pattern, often called the "process mark" or "process signature", is left on the surface by the process. For most processes, the tool mark is sensitive to the process parameters and the machine tool conditions, which can thus be diagnosed from measurement of the irregularities from the process mark on the surface. The diagnosis can be made more efficiently and frequently through on-machine surface metrology of the workpiece itself, without using an additional artefact, or moving the workpiece from the machine tool. For this task, it is required to establish the relationship between the surface irregularities, the process parameters and machine tool conditions.

The tasks and corresponding requirements for on-machine surface metrology are summarized in Table 1. Fig. 7 shows the technology chain for surface metrology. Most of the technologies require specific modifications for on-machine conditions, which will be presented in the following sections. Surface characterization will not be included in this paper since it is basically common for on-machine and off-machine metrology and has already been covered in Refs. [15,36,111].

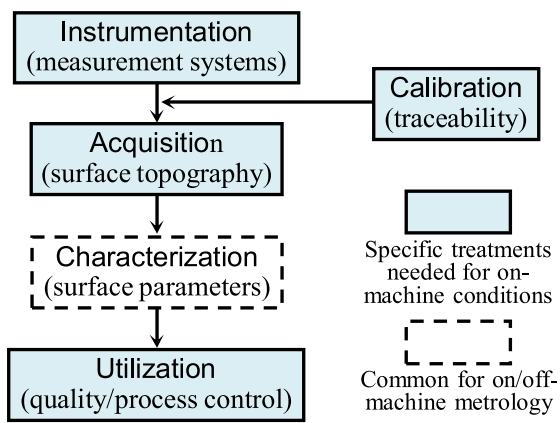

Fig. 7. Technology chain of surface metrology.

\section{On-machine measurement systems}

The on-machine measurement systems to be presented in this section are listed in Fig. 8 with a brief summary of the major types of surfaces and environment that the systems can be applied for.

Measurement systems for on-machine and in-process surface metrology can be classified into full-field systems and probe-scan systems. In an on-machine full-field system, which is usually an optical system, a light beam is projected onto a certain area of the workpiece surface for capturing the three-dimensional (3D) topographic information over an area, which is often referred to as the field of view of the system. In an optical microscope for fullfield texture measurement, an objective lens is employed to collect the light beam from a small area to improve the lateral resolution.

Table 1

Tasks and requirements for on-machine surface metrology.

\begin{tabular}{|c|c|}
\hline Tasks & Requirements \\
\hline For workpiece initial alignment and positioning & $\begin{array}{l}\text { - Unification of the coordinate system of measurement and } \\
\text { that of the machine tool } \\
\text { - Sufficient positioning accuracy }\end{array}$ \\
\hline For workpiece quality control & $\begin{array}{l}\text { - Establishment of specific sampling strategies for probe-scan } \\
\text { measurement systems } \\
\text { - High measurement speed to follow the machining operation }\end{array}$ \\
\hline For compensation machining & $\begin{array}{l}\text { - Modelling of the surface measurement data and generation of } \\
\text { modified NC path data for compensation machining } \\
\text { - Making transferring of the feedback data into NC controller of machine } \\
\text { tool by direct numerical control (DNC) }\end{array}$ \\
\hline For process and machine tool diagnose & $\begin{array}{l}\text { - Making clear the relationship between the surface irregularities and the } \\
\text { process parameters and machine tool conditions }\end{array}$ \\
\hline
\end{tabular}

Common requirements

- Compact sensor size due to the limited space of the machine tool

- Robust to the severe manufacturing environment

- Sufficient resolution and accuracy along the vertical and lateral directions

- Identification of the position of the sensor head within the machine tool coordinate system

- Taking use of the position data of the slide and spindle from the NC controller of machine tool

- Hardware and software interfaces for communication with the NC controller of machine tool 
In an on-machine probe-scan system, a $1 \mathrm{D}$ or $2 \mathrm{D}$ probe, either contact or noncontact, is moved by the machine tool axes for scanning the workpiece surface in a point-by-point or a continuous-path mode. Surface texture measurement can be realized by scanning a mechanical or optical stylus with a small footprint. Table 2 shows the features of the two kinds of systems in terms of machine tool integration, workpiece flexibility, measurement speed, cost and uncertainty sources.

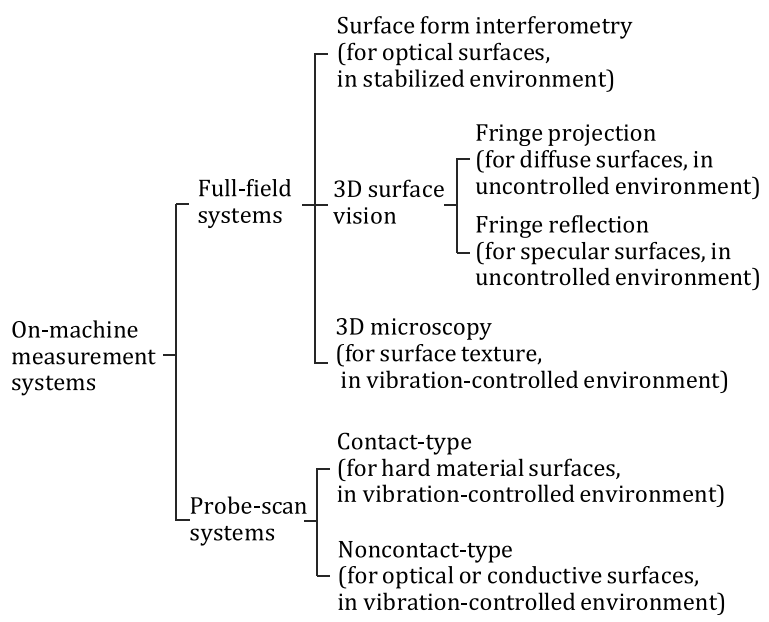

Fig. 8. Measurement systems for on-machine surface metrology.

Table 2

Features of on-machine full-field and probe-scan systems.

\begin{tabular}{cl}
\hline Full-field & - Difficult-to-mount on machine tool due \\
systems & to large instrument size. \\
& - Instrument size proportional to measurement \\
& area of workpiece surface \\
& - Short measurement time but high instrument cost \\
& - Uncertainty sources: machine tool vibrations, \\
& air disturbances, calibration errors, etc. \\
Probe-scan & - Easy-to-mount on machine tool due to small probe size \\
systems & - Flexible in workpiece shapes and measurement areas \\
& - Low probe cost but long measurement time and \\
& requirement on interaction with NC controller of \\
& machine tool \\
& - Uncertainty sources: motion errors of machine axes, \\
& probe alignment errors, thermal drift, vibration, etc.
\end{tabular}

\subsection{On-machine full-field measurement systems}

\subsubsection{On-machine full-field systems for surface form}

On-machine full-field measurement of the surface form of a precision workpiece can be carried out by a surface form interferometry system or a 3D surface vision system (Table 3). Surface interferometry, most often Fizeau or Twyman-Green interferometry, has long been employed for ex-situ testing of optics for its high form measurement accuracy. When applying surface interferometry on a machine tool, it is important to reduce the influence of environmental disturbances, such as machine vibration and air turbulence, which is typically more significant under on-machine conditions, for stabilizing and analyzing the interferograms. On the other hand, although substantial improvements in the performance of 3D surface vision systems have been achieved in recent years, with advances in camera and image processing technologies, the form measurement accuracy is still much lower than that of surface interferometry systems. How to realize accurate calibration on a machine tool is another important issue for on-machine applications of a 3D vision system.

3.1.1.1. On-machine surface form interferometry. In surface interferometry, an interferogram, which is a stationary interference fringe field corresponding to the distribution of optical path difference (OPD) between the workpiece surface and a reference surface, is generated based on two-beam interference. An intensity image of the interferogram is captured by an image sensor for analysing the height information of the workpiece surface in terms of light wavelengths [250]. Due to the limitation in the frame rate of the image sensor, it takes a certain period of shutter time, typically ranging from $0.2 \mathrm{~ms}$ to $10 \mathrm{~ms}$ [266], for the camera to capture the data frame over the field of view of the image sensor. Any changes in the interferogram, i.e. the OPD distribution during the shutter time, which can be caused by air turbulence and machine vibration, will thus result in a change of the captured data frame and, consequently, an error in the surface form measurement.

Therefore, vibration and air turbulence for on-machine surface form interferometry must be stabilized within the frame rate. The Fizeau interferometer is the most used surface interferometer for ex-situ measurement of flat workpieces as the dead path can be made small so the sensitivity to air temperature- and pressure effects is minimal [250]. The Fizeau interferometer can also be extended for measurement of spherical and aspherical surfaces. In a Fizeau interferometer, the reference path is common with the measurement path, except for the non-common measurement path that is twice the surface separation between the reference flat and the workpiece. In an ex-situ measurement, a nearly commonpath configuration is typically taken by setting a small surface separation, which makes it easier to achieve a stable interferogram than other types of interferometers [181].

Fig. 9 shows one of the first on-machine applications of interferometry by using a Fizeau configuration [181]. The interferometer was mounted at a position on the machine bed to measure the diamond-turned flat workpiece. After the machining, the tool, which was located between the interferometer and the workpiece, was moved away so that the form could be measured. This

Table 3

Features of on-machine full-field systems for surface forms.

\begin{tabular}{|c|c|}
\hline $\begin{array}{l}\text { On-machine surface form } \\
\text { interferometry }\end{array}$ & $\begin{array}{l}\text { - Working principle: two beam interference } \\
\text { - Vertical resolution: } 1 / 1000 \text { wavelength }(\lambda) \\
\text { - Limited to near-flat or near-spherical workpiece surfaces with small slope variations, possible for aspheric } \\
\text { surfaces with customized computer generated hologram (CGH) } \\
\text { - Mainly for final workpiece inspection and feedback machining } \\
\text { - Uncertainty sources: environmental disturbances (machine vibration, air turbulence, temperature variation, etc.) }\end{array}$ \\
\hline On-machine 3D surface vision & $\begin{array}{l}\text { Stereo photogrammetry/fringe projection } \\
\text { - Work principle: triangulation } \\
\text { - Vertical resolution: } 1 \mu \mathrm{m} \\
\text { - Limited to diffuse reflection surfaces, without modification of optics } \\
\text { - For initial alignment of workpiece, measurement of rough surfaces } \\
\text { - Uncertainty sources: surface interaction, phase unwrapping, calibration error, low vertical resolution, etc. } \\
\text { Fringe reflection (deflectometry) } \\
\text { - Work principle: law of reflection } \\
\text { Slope resolution/vertical resolution: } 0.1 \text { arc-seconds/1 nm } \\
\text { - Limited to specular reflection surfaces } \\
\text { - For measurement of freeform surfaces } \\
\text { - Uncertainty sources: phase unwrapping, calibration error, etc. }\end{array}$ \\
\hline
\end{tabular}


configuration required a large surface separation between the workpiece and the reference flat of the interferometer, which could be realized by the long coherence length of the laser source, but, the large surface separation significantly increased the noncommon path length between the reference and the measurement beams. This is a major difference from an ex-situ Fizeau interferometry system, where a nearly common-path configuration is achievable. For this reason, the on-machine interferogram became sensitive to environmental disturbances. To reduce the influence of vibration, the machine was isolated from outside vibration by using air suspensions. During the measurement, the machine was completely stopped and was covered with a vinyl sheet for further reduction of the influence of vibration and air turbulence. Under this condition, a data frame could be captured with a stability of $1 / 20$ wavelength $(\lambda)$.

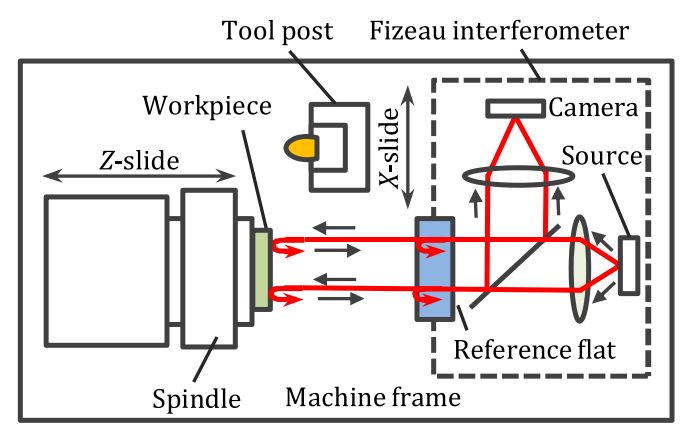

Fig. 9. Schematic of a Fizeau interferometer on a diamond turning machine (modified from Ref. [181]).

The phase-shifting technique has become a well-adopted analysis technique of interferograms for calculating the surface height information, with a high vertical resolution in almost all kinds of interferometers [250]. In a phase-shifting interferometer (PSI), the reference surface is stepped by an actuator, often piezoelectric (PZT), with a fraction of a wavelength for recording a set of data frames of interferograms (typically three or four) with precise phase shifts. A vertical resolution of better than 1/ $1000 \lambda$ can be achieved and the form measurement accuracy can be very close to that of the reference flat in a well-controlled exsitu environment. However, under on-machine conditions, incorrect phase shifts between the recorded data frames can be caused by the machine vibration and air turbulence, resulting in large measurement errors of surface form. It should be noted that the phase shift is sensitive to both high-frequency and lowfrequency disturbances, since it takes a relatively long time, typically tens of seconds, to capture the set of the phase-shifted data frames.

For the above reason, a motivation for anti-vibration and air turbulence in on-machine surface form interferometry is for stabilization of the phase shifts between the data frames for the phase-shifting analysis. This can be done by using the single-shot phase measurement method, where the set of phase-shifted data frames are captured simultaneously. Such an interferometer is often called a dynamic interferometer [14]. A Twyman-Green dynamic interferometer has been commercialized for on-machine surface metrology [228]. Owing to the compact Twyman-Green configuration and the robust single-shot phase measurement method to environmental disturbances, the interferometer can be directly mounted on the tool post, side by side with the cutting tool, for easy access to the workpiece without special vibration isolation and air turbulence control (Fig. 10).

The actively stabilized PSI is also effective for on-machine surface form metrology [249]. In this method, the phases at each phase step are actively stabilized by either changing the frequency of a diode laser source through its injection current, or by changing the position of the reference mirror with a PZT actuator based on the measurement result of workpiece vibration by an embedded common-path displacement interferometer [248,254].

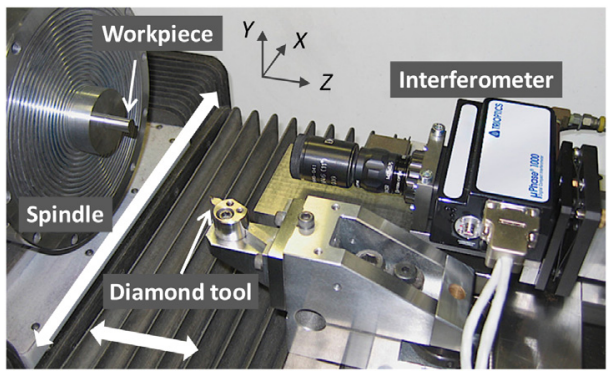

Fig. 10. An on-machine Twyman-Green dynamic interferometer [228]

A more ideal way of reducing the effects of vibration and air turbulence for on-machine surface form interferometry is to employ a common-path interferometer [243] or a simplified near common-path configuration [110,251]. In a common-path interferometer, the reference beam and the measurement beam travel along the same path. In an on-machine zone-plate interferometer, a zone-plate [180], which is a CGH with circular diffraction structures, serves as a beam splitter to divide the illumination beam into the zeroth and the first order beams, working as the reference beam and the measurement beam, respectively. Since the reference and measurement paths are common, the generated interferograms are only minimally influenced by machine vibration and air disturbances. It has been demonstrated that stable interferograms were obtained when a spherical workpiece was being rotated by the spindle at a rotational speed of $900 \mathrm{rpm}$, which was the same as the speed for cutting the workpiece [180]. Since an asymmetric wavefront can be generated by the CGH to match the measured surface, not only flat and spherical, but also aspheric surfaces can be measured on the machine by such a CGH common-path interferometer. Fig. 11 shows an on-machine common-path interferometry system for a horizontal surface grinding machine [120]. A vertical configuration was used for the measurement system, where the interferometer was mounted on a stand independent from the machine to measure the aspherical workpiece surface that was located about $10 \mathrm{~m}$ below the interferometer. The first order diffracted beam generated at the CGH was projected on to the workpiece. The zeroth order diffracted beam transmitted by the CGH was passed to a smaller reference mirror mounted on the table of the machine beside the workpiece. The on-machine measurement system has been applied for grinding the segments of a $3.8 \mathrm{~m}$ telescope primary mirror.

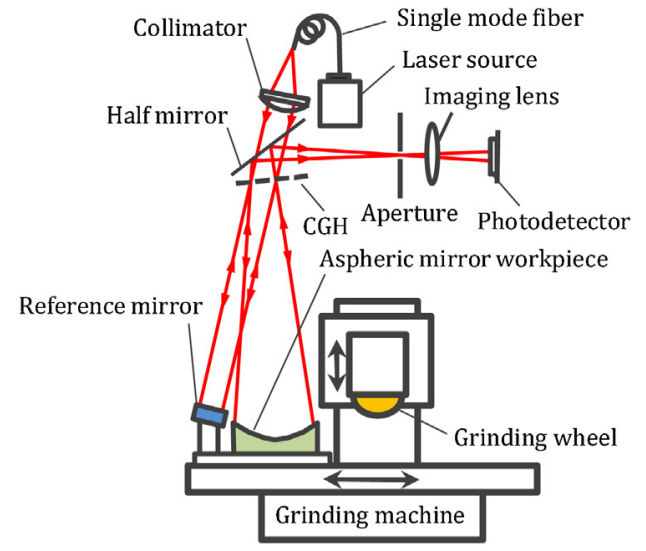

Fig. 11. An on-machine common-path interferometry system for a horizontal surface grinding machine [120].

In addition to the above approaches associated with modifications of the hardware and configuration of an interferometer, reduction of machine vibration and air-turbulence for on-machine surface interferometry was also attempted from the approach of software compensation with a standard interferometry configuration. A spatial phase measurement method associated with a fast Fourier transform (FFT) algorithm was developed for a Twyman- 
Green interferometer mounted an injection molding machine for on-machine surface measurement of a mold insert (Fig. 12) [201].

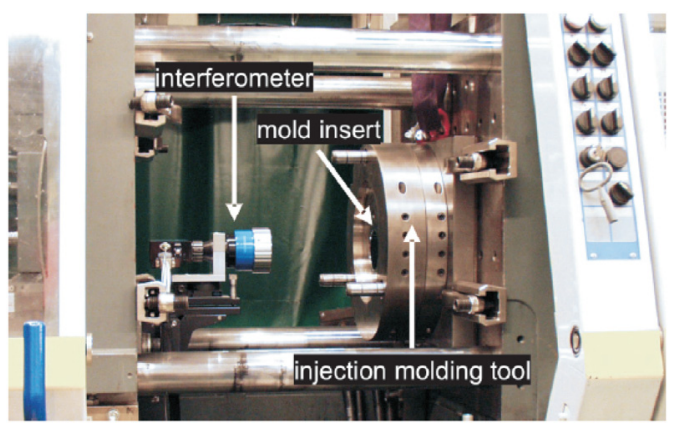

Fig. 12. An on-machine Twyman-Green interferometer with a fast Fourier transform (FFT) algorithm for an injection molding machine [201].

3.1.1.2. On-machine $3 D$ surface vision. Stereo vision is the most popular vision technology for 3D measurement based on 2D stereoscopic images [21]. Stereo vision can be categorized as active and passive vision systems, which respectively operate with or without active illumination of the workpiece surface.

\section{Passive stereo vision (stereo photogrammetry)}

In passive stereo vision, also called stereo photogrammetry, the 3D topographic information of a number of points on the surface is reconstructed from images taken by two or more digital cameras. Fig. 13 shows the simplest case with two identical cameras. Each of the cameras has a lens of a focal length $f$ and a CCD or COMS image sensor of width $S$. A pinhole camera model is employed for simplicity of description. The cameras with a lateral separation of $b$, called the baseline length, are employed to take a pair of stereoscopic images of the surface over the same field of view of $D$ (the maximum field of view $D_{\max }$ is shown in the figure). Then a pair of image points $M_{L}$ and $M_{R}$ are matched in the two images corresponding to the same surface point $M$ on the workpiece, which is referred to as binocular stereo matching. The 3D coordinates $(x, y, z)$ of point $\mathrm{M}$ can thus be obtained from the $2 \mathrm{D}$ coordinates $\left(x_{\mathrm{L}}, y_{\mathrm{L}}\right)$ and $\left(x_{\mathrm{R}}, y_{\mathrm{R}}\right)$ of the image points, based on the principle of triangulation [65], with the information of the baseline length $b$ and the focal length $f$ of the cameras. Note that the coordinates in the $Y$-direction are not shown in the figure for clarity. $w_{\max }$ and $w_{\min }$ are referred to as the maximum and minimum working distances, respectively. The difference between $w_{\max }$ and $w_{\min }$ is referred to as the measurement range in the $Z$ direction. All the surface points in this range are visible to both the cameras, which are referred to as binocularly visible points and, therefore, can be detected by stereo photogrammetry.

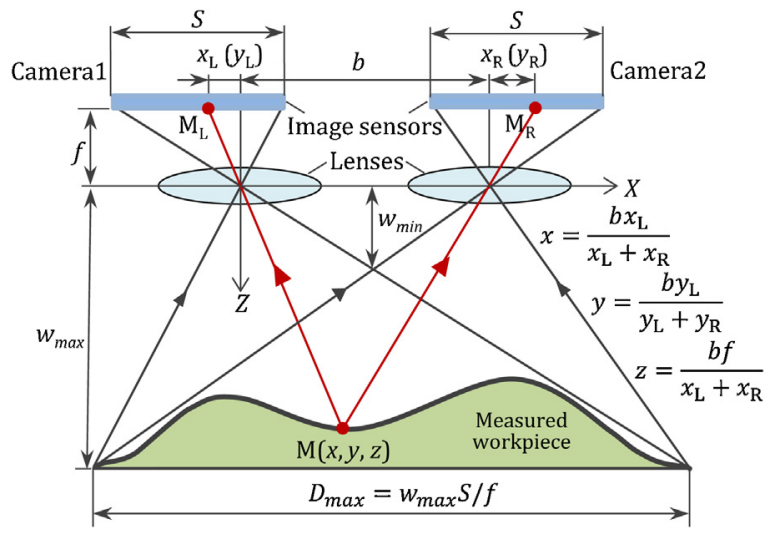

Fig. 13. Principle of passive stereo vision (stereo photogrammetry).

Since the binocular stereo matching is only possible for well textured surface regions and/or surface points with clear features, such as edges and corners, one possible application of on-machine stereo photogrammetry is for tool wear measurement (although it is possible to apply a pattern to allow smooth surfaces to be measured [212]). Niranjan and Ramamoorthy mounted a camera on a high-speed lathe to measure the 3D contour of crater wear of an uncoated carbide tool inset on high carbon alloy steel [177]. The pair of stereo images were acquired by moving the tool to two different positions. The on-machine vision system could distinguish a crater wear with a $39 \mu \mathrm{m}$ depth. Stepped patterns with varying depths of 150,300 and $450 \mu \mathrm{m}$, which were ground on a cuboidal block, were used to calibrate the vision system.

On-machine stereo photogrammetry can also be employed to perform the task of initial workpiece alignment, where the 3D position of the workpiece in the machine tool coordinate system is identified from the 3D coordinates of clear surface features or additional artefacts mounted on the surface. Tian et al. mounted such a system on the frame of a five-axis machining centre to identify the 3D edges of a workpiece from which the 3D position of the workpiece is recognized in the machine tool coordinate system with an accuracy of $1 \mathrm{~mm}$, so that machining setup modelling and tool path generation can be made to prevent possible collisions in the machining process [224]. Zatarain et al. developed a spindle-mounted stereo photogrammetry system for initial alignment of large cast and welded raw workpieces on a milling machine, where the excess material of the raw workpiece with respect to the final shape had to be distributed with an accuracy better than $5 \mathrm{~mm}$ with respect to the surfaces to be machined [264]. A camera was mounted on the tool holder of the machine. The pair of stereo images of the workpiece mounted with artificial targets were obtained by moving the camera with the machine slides to two different positions. A self-calibration technique was developed for the system [165].

\section{Active stereo vision (fringe projection)}

To make the stereo matching effective at all points on the workpiece surface for 3D surface topography measurement, it is necessary to employ a laser or a structured light pattern to actively illuminate the surface, which is referred to as active stereo vision. In structured light stereo vision, one of the cameras in Fig. 13 is replaced with a projector that generates a spatially varying $2 \mathrm{D}$ structured illumination pattern on the surface. A distorted image of the projected structured light pattern, corresponding to the 3D surface topography, is formed at the image plane of the camera. The 3D surface topography can be reconstructed from single- or multi-shot techniques [21], based on the same triangulation principle as in Fig. 13.

As an early application, Giusti et al. employed fringe projection for tool wear measurement on an NC lathe [78]. The flank wear and the crater wear of a cutting tool insert could be measured with vertical resolutions of $10 \mu \mathrm{m}$ and $20 \mu \mathrm{m}$, respectively. Commercial fringe projection systems have been developed for surface flatness measurement of flat rolled steel strips on hot or cold strip mills [169]. A vertical resolution of $1 \mathrm{~mm}$ can be achieved for a maximum strip speed of $20 \mathrm{~m} / \mathrm{s}$ and a maximum strip temperature of $1100^{\circ} \mathrm{C}$ [96]. Fringe projection has also been applied to in-process surface metrology in metal additive manufacturing. Fig. 14 shows a typical setup of in-process fringe projection in laser powder bed fusion manufacturing (LPBF) [255]. The lateral resolution of the employed fringe projection system was $10 \mu \mathrm{m}$ achieved by using a digital camera with pixel numbers of $4096 \times 2160$ and a $50 \mathrm{~mm}$ lens. The camera was aligned approximately $200 \mathrm{~mm}$ above the powder bed, providing a field of view of $28 \times 15 \mathrm{~mm}$.

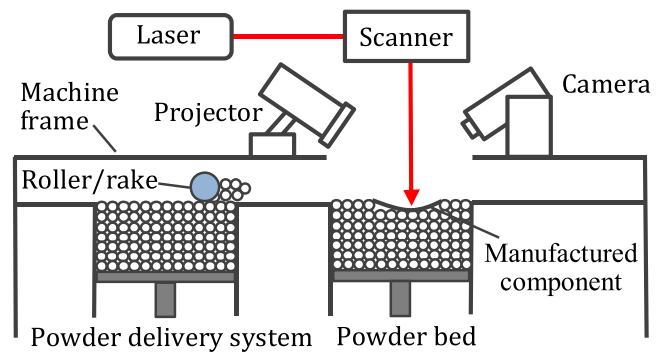

Fig. 14. A typical fringe projection system for in-process surface metrology in laser powder bed fusion additive manufacturing. 
One of the most significant drawbacks of stereo vision techniques, either active or passive, is the low resolutions in both vertical and horizontal directions due to the triangulation configuration and the limitation in the resolution of the CCD or COMS image sensor [118]. A $1 \mu \mathrm{m}$ vertical resolution and a $10 \mu \mathrm{m}$ lateral resolution has been achieved in a state-of-the-art small volume fringe projection 3D surface vision system with a $1408 \times 1408$ pixel CMOS image sensor by reducing the horizontal field of view and the vertical range to be approximately $12 \mathrm{~mm} \times 12 \mathrm{~mm}$ and $3 \mathrm{~mm}$, respectively [118]. However, the resolutions get worse when the horizontal field of view and the vertical measurement range become larger. This resolution issue is a major obstacle to apply the stereo vision techniques to highprecision on-machine surface metrology.

Fringe reflection (fringe deflectometry)

In stereo vision, all the surface points of the workpiece must be imaged at the image plane of the camera. This requires an incident ray on the surface to be diffusely reflected at each of the surface points so that a part of the reflected light from the point can be collected by the lens of the camera for the image formation. A different technique of 3D surface vision, such as the fringe reflection vision (also called fringe deflectometry) shown in Fig. 15, is therefore necessary for measurement of a workpiece surface with specular reflection, where an incident ray on the surface is only scattered in one direction following the law of reflection. Fringe deflectometry can be realized by removing the projection lens in a fringe projection system. A series of encoded fringe patterns displayed on a light screen, which can be a liquid crystal display (LCD) or a rear projection screen associated with a projector, are observed by the camera after the fringe patterns are reflected by a workpiece surface with specular reflection [188]. The images of the fringe patterns will be distorted by the slope variations of the surface. Differing from stereo vision, where the surface height information is directly obtained based on the principle of triangulation, the distorted images in fringe reflection are decoded to obtain the surface slope information based on the law of reflection from which the surface height is calculated by a mathematical integration process. This technique can be traced back to slope methods, such as the Foucault knife edge test, the Hartmann or Hartmann-Shack tests, the Moire reflection method and the grating reflection method. It is also analogous to laser autocollimation [42], where a laser beam is scanned over a mirror surface to detect the local surface slope for surface profile measurement.

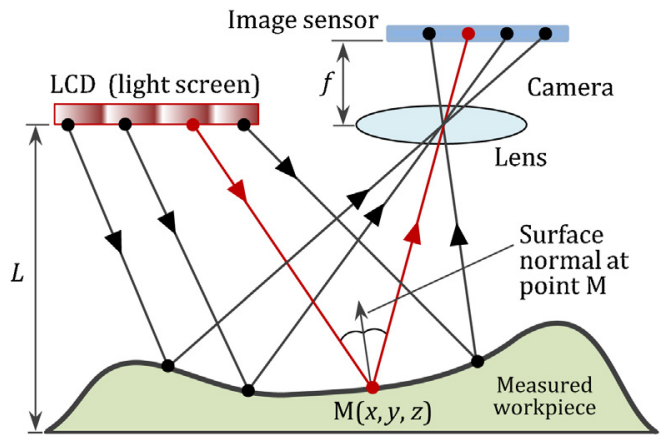

Fig. 15. Principle of fringe reflection vision (fringe deflectometry).

Perard and Beyerer developed one of the first fringe deflectometry systems for measurement of small waviness components and curvature errors of freeform surfaces with specular reflection based on the fact that fringe reflection vision is particularly sensitive to slope variations of the surface [188]. A grey-code of binary fringe patterns was employed in the system to reduce the occurrence of decoding errors and to avoid the phase unwrapping problem that occurs with the spatial phase shifting methods. However, the performance of the system was also limited by the simple binary coding and encoding methods. Consequently, it was difficult to detect a surface variation on a polished metal plate with a depth of $15 \mu \mathrm{m}$ and a lateral dimension of $2.5 \mathrm{~cm}$.
The performance of fringe deflectometry has been significantly improved by implementing the phase shifting technique [91]. In this phase modulation deflectometry or phase measuring deflectometry (PMD), $N$ (typically four) sets of sinusoidal fringe patterns with a phase shift of $2 \pi / N$ are projected onto the workpiece surface. The local slope at a surface point can be obtained by identifying the corresponding screen pixel coordinate from the $N$ intensity values recorded by a camera pixel, based on a phase shifting algorithm. Sinusoidal fringes rather than binary fringe patterns are adopted since a sinusoidal fringe does not change its phase even at a defocused position of the camera [125]. This makes it possible to focus the camera on the workpiece surface, while capturing a high contrast image of the fringe, resulting in an improvement of resolution and a reduction of measurement uncertainty. A stereo deflectometry method with two cameras was also proposed to solve the problem of ambiguity in identification of the surface normals. Such a system could reach a repeatability of local slope measurement down to a few arc-seconds. The measurement accuracy could reach to the sub-micrometre range on a field of view of $100 \mathrm{~mm}$ and even higher for a smaller field of view. This has expanded the applications of fringe deflectometry systems into measurement of precision workpieces with specular reflection surfaces, such as aspheric or freeform optics, including progressive eyeglass lenses where the surface curvature is of interest [91].

Whilst a deflectometry system is sensitive to the local slopes of the surface, it is insensitive to the vertical position of the surface, i.e., changes of vertical position caused by vibration. For example, it was demonstrated that a PMD can work stably under vibration with amplitudes up to several wavelengths [49]. This is a significant advantage for applications in on-machine surface metrology. The PDM has been miniaturized by using a $20.1 \mathrm{in}$. TFT monitor as the light screen, so that it could be used inside the limited working space of a diamond turning machine, as shown in Fig. 16 [48]. The miniaturization also limited the field of view and the maximum slope measurement range to be $25 \mathrm{~mm}$ in diameter and $\pm 10^{\circ}$, respectively. The lateral resolution of the system was $25 \mu \mathrm{m}$ per pixel, for a working distance of $120 \mathrm{~mm}$. The PDM can be mounted on the $B$-axis and on the machine frame with switchable measurement and stand-by positions. By using the $C$-axis of the machine to reposition the workpiece between several single measurement sequences, the field of view and slope measurement range can be increased.

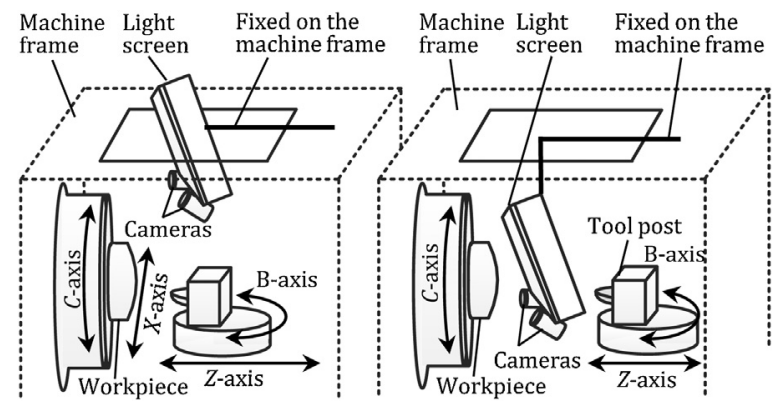

Fig. 16. Fully machine integrated setup of a PMD in stand-by position (left) and in measurement position (right) (modified from Ref. [48]).

Surface deflectometry was further optimized based on the concept of a computerized reverse Hartmann model for onmachine measurement of large concave aspheric mirrors, such as solar collectors and primary mirrors for astronomical telescopes [182]. The light screen and the camera are placed close together and near the centre of curvature of the mirror. This is near astigmatic condition where the sensitivity to the camera position information and that to the camera lens distortion are greatly reduced. In addition, a small camera aperture is employed so that each camera pixel only receives the light from a small number (three to five) of screen pixels. Consequently, the screen size is reduced to approximately equal to twice the product of the aspheric slope (the gradient of the aspheric departure) and the radius of curvature. A smaller screen size leads to smaller pixels 
and, therefore, provides a higher sensitivity and accuracy of screen pixel coordinates. With careful calibration, the system can achieve measurement accuracy comparable with interferometric methods in the mid-spatial frequency range of the surface [154]. The system was mounted in the fabrication/inspection facility of the $4.2 \mathrm{~m}$ offaxis aspheric primary mirror of Daniel K. Inouye Solar Telescope (DKIST) to measure the polished mirror surface for the task of compensation machining [182]. A LCD display and two cameras were employed to generate the fringe patterns and capture the reflected fringes, respectively.

In addition to the phase shifting method, a line-scan method has also been implemented, in which only one line of screen pixels is lit up as a line source along the $x$ or $y$ directions at each time [215]. Based on the reverse Hartmann model, the surface $x$ or $y$ slope at a certain surface point can be determined without the ambiguity in mapping the relationship between the surface points and the corresponding screen pixels. By lighting up the screen pixels line-by-line in $x$ and then in $y$, the full mirror surface slope map can be obtained. This method has been utilized in an infrared (IR) deflectometry system, where a heated tungsten filament wire was employed as the infrared line source and a micro bolometer array as the camera. The IR system is effective for measurement of the ground glass mirror surfaces that are diffuse for visible wavelength light. It has been demonstrated that the ground surface of the DKIST mirror could reach to a $1 \mu \mathrm{m}$ form accuracy after compensation grinding, based on the measurement results by the IR system [182].

As a recent application of on-machine fringe deflectometry, an alignment/positioning method for optical freeform workpieces has been proposed to improve the accuracy of remounting the workpiece on a five-axis ultra-precision machine for compensation machining (Fig. 17). Sinusoidal fringe patterns with a pitch of $7.68 \mathrm{~mm}$ were generated from a $9.7 \mathrm{in}$. LCD display with a pixel size of $96 \mu \mathrm{m}$. The phase similarity and phase range of the fringes were used to obtain the six degree-of-freedom position information of a re-mounted cubic phase plate surface with a sag value of $31.25 \mu \mathrm{m}$ and an aperture of $20 \mathrm{~mm}$. The angular and linear positioning accuracy were identified to be $0.005^{\circ}$ and $5 \mu \mathrm{m}$, respectively [258]. A similar application has been reported for alignment of multi-segmented mirrors on a polishing machine [31]. A CMOS camera captured images of reflected 2D sinusoidal patterns from seven multi-segmented mirrors for measurement of the surface orientations of the mirror segments with a resolution of 0.16 arcseconds in a time of $0.07 \mathrm{~s}$, based on which the alignment of each mirror segment was carried out.

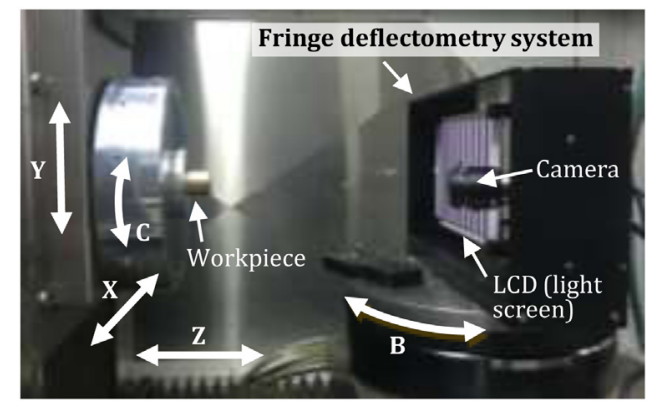

Fig. 17. An on-machine fringe deflectometry system for alignment of a freeform workpiece [258].

Measurement based on fringe deflectometry is influenced by the fringe pattern accuracy, the intrinsic parameters of the camera (such as the pixel number, the lens distortion and aberration), and the relative positions of the light screen, the camera and the measured surface. Calibration is thus an important procedure before the use of a fringe reflection system for on-machine measurement, especially the calibration of the light screen, the workpiece and the camera under the machine coordinate system.

\subsubsection{On-machine 3D microscopy for surface texture}

Optical microscopy is the only full-field technology that can be used for 3D measurement of surface texture on the microscopic scale under on-machine conditions [20,144]. Most of the existing 3D optical microscopy techniques [94,134], such as interference microscopy, focus variation microscopy, and confocal microscopy, have the potential to be employed for on-machine measurement.

In 3D optical microscopy, the magnification of the surface area in the lateral directions is made by using the objective as an imaging lens. This is basically the same as 2D optical microscopy that has been employed for on-machine measurement of edge contour profile, such as a tool [260], a micro-hole [176] or a die coater slit [59]. The lateral resolution is determined by the size of the field of view and the number of the camera pixels or by the diffraction limit, depending on the aperture used. For making the measurement along the vertical direction, it is generally necessary to mechanically scan the objective along the vertical direction by using an actuator, or to electronically scan the wavelength of the light source, for the camera to take a series of images of the surface. For example, in focus variation microscopy, the objective with a small depth of field is vertically moved along the optical axis by using a scanner, while the images of the surface are continuously captured. Due to the limited depth of focus, only the in-focus areas of the surface are sharply imaged, based on which the height information of the surface can be obtained [34].

In coherence scanning interferometry, the interferogram images from a vertically scanning interference objective such as a Mirau objective are continuously captured and the surface height at a point can be obtained by identifying the vertical position of the objective where the envelope peak position of fringes, i.e., the minimum optical path difference between the reference path and the measurement path, is reached at the corresponding image pixel [85]. Similar to the phase-shifting surface form interferometer described in Section 3.1.1.1, where the reference surface is moved along the optical axis by a piezoelectric actuator, a 3D optical microscope is sensitive to vibration of the microscope with respect to the workpiece surface [128]. Taking into consideration the nanometric height resolution of 3D optical microscopy, anti-vibration is thus the most important issue when it is implemented for on-machine measurement.

Based on the fact that a 3D optical microscopes has the possibility to be more compact due to its smaller fields of view compared with a full-field system for surface form, there are some unique antivibration methods, either passive or active, that can be employed for on-machine optical microscopy. One way of passive anti-vibration is to increase the stability of the microscope by mounting it on a rigid position of the machine tool. For example, a white-light scanning interferometer can be mounted on the rigid Z-slide of a grinding machine, next to the workpiece spindle or the grinding wheel [253]. If the measurement is carried out when the operation of the grinding wheel is stopped, a mechanically stable condition can be achieved.

If the workpiece is rigid enough compared to the mass of the microscope, another way to achieve anti-vibration is to directly mount the microscope on the workpiece surface. In this case, the relative position of the microscope with respect to the workpiece surface does not change even in the presence of machine vibration. Fig. 18 shows an on-machine optical microscope specifically designed and implemented for surface texture measurement in polishing of large telescope mirrors [182]. A point source microscope (PSM) with low mass and compact size was developed for this purpose. The microscope was coupled through its circular base to a ring jig sitting

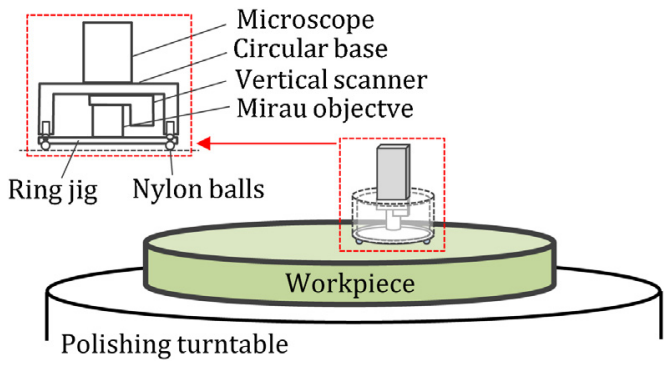

Fig. 18. A point source microscope located on the workpiece surface for passive antivibration (modified from Ref. [182]). 
on the mirror surface via three nylon balls. This makes a stiff connection between the microscope and the measured surface. With the assistance of the on-machine microscopy, a 4.2 diameter large mirror has been super-polished to surface with an $S q$ of $0.1 \mathrm{~nm}$ [182].

For active anti-vibration, it is necessary to measure the relative displacement between the objective and the workpiece surface in real time. As shown in Fig. 19, this can be carried out by using an external reference displacement laser interferometer by attaching a micro-prism on the objective, as demonstrated by Chen et al. [22]. A better way is to embed an internal reference displacement interferometer that has a common path and is co-axial with the measurement beam of the microscope so that the Abbe error [65] can be minimized. This is analogous to the concept for actively stabilized PSI discussed in Section 3.1.1.1. Schmit et al. presented two designs based on this concept for coherence scanning interferometry, as shown in Fig. 19 [200]. In the first design, a part of the measurement beam is divided by a beam splitter for use in the internal reference displacement interferometer, where the light is passed through a narrow bandwidth filter (NBF) and received by a photodetector (PD1). Although this design is simple and inexpensive, the filter needs to be judiciously selected to provide enough spatial coherence to cover the entire range of the objective scan. The low signal level of the reference interferometer is another drawback of this design.

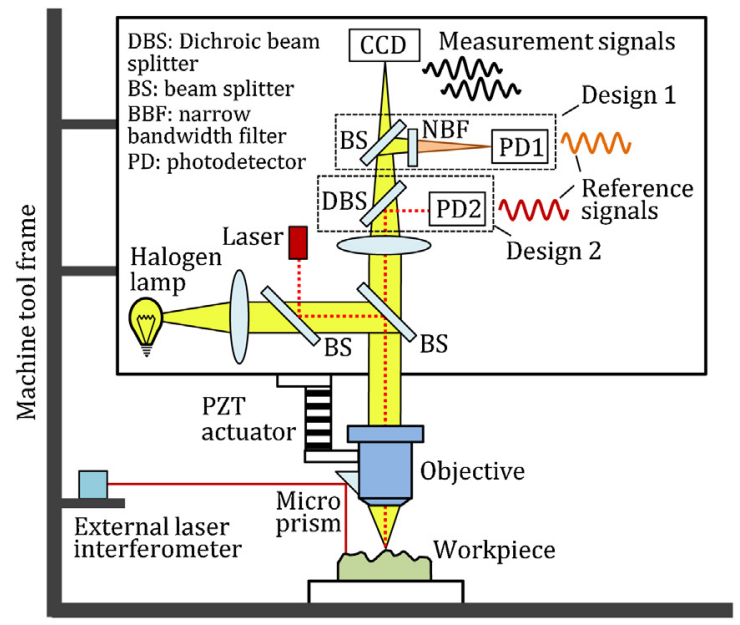

Fig. 19. External and internal reference displacement interferometers in 3D microscopy for active anti-vibration (modified from Refs. [22,200]).

In the second design of Fig. 19, a high coherence source, such as a laser, is added for as an independent internal reference displacement interferometer that shares the optical path of the microscope measurement beam. A dichroic beam splitter (DBS) is employed to separate the long and short coherence beams so that the former can be received by PD2 of the reference interferometer. Compared with the first design, the small beam diameter and the narrow wavelength bandwidth of the long coherence source produces a higher quality interference signal for the displacement measurement, making the measurement more accurate and robust. A similar design has been employed in a phase-shifting white-light interference microscope [147] and a wavelength scanning interference microscope $[107,109]$, both using superluminescent diodes (SLDs) as the high coherence sources. Muhamedsalih et al. demonstrated the potential of the latter for measurement of a micro-structured master drum on a diamond turning machine, and characterization of the atomic layer deposition vapour barrier films in a roll-to-roll process [172]. Chen et al. simplified this type of design [22]. Instead of using an additional high coherence source, a narrowband-pass filter with a annular aperture was inserted in to the illumination path of a white-light source so that the low-coherence light passes through the central circular region, while the high coherence light passes through the outside annular region. A band-pass filter of $452 \mathrm{~nm}$ with bandwidth of $5 \mathrm{~nm}$ was employed to generate a coherence length of $40 \mu \mathrm{m}$ in the experiment.

\subsection{On-machine probe-scan systems}

An on-machine probe-scan system for surface metrology is established by combining a probe (a 1D or 2D displacement sensor or a slope sensor) and the moving axes of a machine tool. The surface topography height information is provided by the probe itself while the lateral positions of the measuring points are determined by the machine axes that scan the probe over the workpiece surface in a point-by-point or a continuous-path mode. The height measurement range can also be extended by utilizing the positioning capability of the machine axis that is co-axial with the probe axis. Compared with on-machine full-field measurement systems, on-machine probescan systems are more flexible in terms of measurable shapes and sizes of workpiece. However, in addition to vibration, the mounting/ alignment errors of the probe as well as the error motions of the machine axes have to be taken into account as the major sources of measurement uncertainty [146]. Thermal drift of the probe output and thermal expansion of the workpiece and the machine tool are also uncertainty sources due to the time-consuming scan operation.

\subsubsection{Probes for on-machine surface metrology}

There are a large variety of probes that have already been employed or have the potential to be employed for on-machine surface metrology. Some are shown in Fig. 20 and will be presented in this section, with the exception of on-machine tactile probing systems that have been reviewed by Weckenmann et al. [235] and are widely used in various types of precision machine tools [93,192].

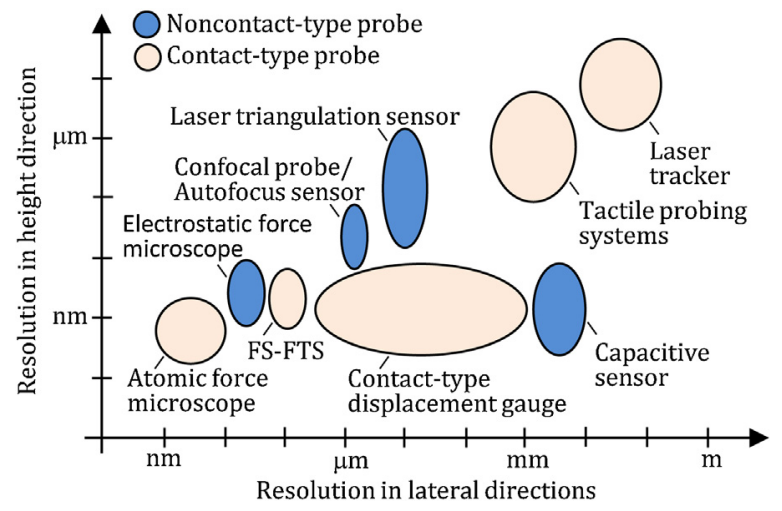

Fig. 20. Probes for on-machine surface metrology.

The probes can be categorized as contact and noncontact types, each having its own advantages and limitations. For example, the major advantage of a contact-type probe is its robustness to surface properties, making it even possible for in-process metrology [210]. A further advantage is the simple-to-understand probe-surface interaction that makes traceability of contact probes easier to achieve than optical probes. However, the possible damage to the surface and the slow speed are the main drawbacks of such probes.

The resolution and range of a probe in the height direction is determined by that of the length measurement transducer of the probe. The resolution in the lateral directions is determined by the geometry of the probe tip for a contact-type probe, the size of the capacitance sensing area for a capacitive sensor, or the light spot diameter/diffraction limit for an optical probe.

3.2.1.1. Contact-type probes. As indicated by Tyler, the laser tracker is a portable 'frameless' coordinate measuring machine that can be used for workpiece inspection of large workpieces [44] as well as for machine tool calibration [2]. In the measurement, a retroreflector is usually transported manually by an operator to points of interest on the workpiece surface. Due to this labour-intensive and time-consuming operation, the number of measurement points is limited. Laser trackers are, therefore, often employed for the task of positioning/aligning a workpiece on a machine tool, e.g. an aircraft fuselage on a drilling machine [159] or an aircraft wing in a milling machine [142]. In telescope mirror manufacturing, where the 
measurement time is not a critical issue, laser trackers can be employed to measure the surface form of a rough ground or polished mirror for guiding the fabrication process until an interferometric testing is applicable to the mirror [17]. In the measurement of such a concave mirror, the laser tracker should be mounted as close as possible to the centre of curvature of the mirror so that the line of sight is normal to the mirror surface, and the influence of the angle encoder measurement errors of the tracker, which is the largest uncertainty source for the measurement, can be minimised [161]. For this purpose, the laser tracker was mounted approximately $22 \mathrm{~m}$ above the surface of a $8.4 \mathrm{~m}$ large off-axis mirror resting on the polishing turntable [265]. Since the distance between the tracker and the sphere-mounted retroreflector (SMR) is measured by a distance-measuring interferometer (DMI), the measurement over such a long distance is significantly influenced by variations in refractive index due to environmental disturbances, as well as by the relative error motions between the tracker and the mirror surface caused by thermal expansion and vibration. An external reference system, including four stand-alone DMIs, mounted on the same platform with the laser tracker was thus added to detect four fixed retroreflectors at the edge of the mirror for compensation. A motor-driven mechanism was also developed to move the SMR over the surface of the mirror under computer control for scanning the surface over 250 points, where the lateral position of the SMR was detected by using another laser tracker. The surface form measurement accuracy of the $8.4 \mathrm{~m}$ mirror was confirmed to be $0.87 \mu \mathrm{m}$ rms after further calibration of the angular errors [265].

In a contact-type displacement gauge, also referred to as a dial gauge [235] or a length gauge [92], the probe tip is kept in contact with the surface by applying a contact force (measuring force) to the probe shaft. The displacement of the probe shaft along the probe axis is measured by a length measurement transducer. In a conventional contact-type displacement gauge used for comparative measurement of the dimensions of a workpiece, a spring is typically used to push the probe shaft guided by a ball bearing against the workpiece surface for producing the measuring force, where the displacement is measured by a linear variable differential transformer (LVDT) [156]. The force is equal to the product of the displacement and the spring constant, and can be up to $1 \mathrm{~N}$. Such a probe has the advantage of high stability and is suitable for making discrete-point scans over workpieces of hard materials, such as ceramics. The force can be controlled to be constant by using an integral motor to actuate the probe shaft, while the displacement measurement range and resolution can be improved by using a linear encoder [92]. For on-machine measurement of optical surfaces, where much smaller measuring forces are required, McKeown demonstrated a probe design in which the probe shaft was supported by an air bearing that can produce frictionless movement of the shaft and make it possible to generate small measuring forces [163]. This has become the most common design of on-machine displacement gauges for ultraprecision applications $[19,174,218]$. Fig. 21 shows an air bearing probe for alignment of a remounted workpiece [259]. The low viscosity of the air bearing reduces the anti-vibration performance of the probe as well as the scan speed, especially for on-machine measurement of microstructures [141].

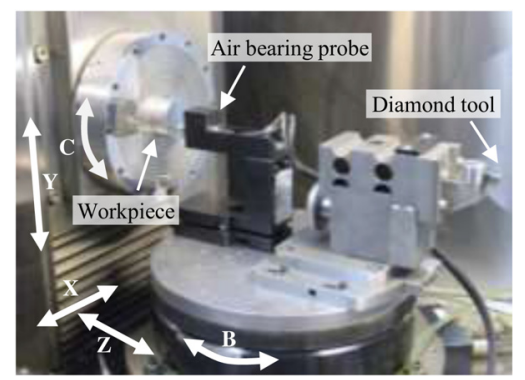

Fig. 21. An on-machine air bearing probe [259].
Some commercially available on-machine air bearing probes are listed in Table 4. In addition to those in the table, Olympus Corporation has developed an ultra-low force air bearing probe based a self-weight method, with a measuring force of $0.05 \mathrm{mN}$, so that a $2 \mu \mathrm{m}$ diameter diamond stylus can be used for on-machine measurement of micro-optics used in endoscopes, without damaging the surface [174]. The probe has been applied for profile measurement of microstructures [245,246] and gears with large surface slopes [247].

Active force feedback control is another approach to reduce the measuring force in a stylus profiler. A force sensor integrated fast tool servo (FTS), which is referred to as the FS-FTS, has been developed to conduct FTS diamond turning, including on-machine measurement of micro-structured surfaces on a diamond turning machine $[140,179]$. By using the FS-FTS, the diamond cutting tool, which has been conventionally only used for fabrication of microstructures, is employed as a force-controlled measuring stylus to measure the cross-sectional profile of the fabricated microstructures with a constant measuring force of $0.15 \mathrm{mN}$ by the same diamond tool, without using an additional surface measuring instrument (Fig. 22) [62]. Such measurement technology was also used for on-machine measurement of cutting edge contours of single point diamond tools $[25,28]$ and initial surface form of brittle workpieces [26] as well as for in-process measurement and repair of defective microstructures [29].

The measuring force can be further decreased in an AFM, together with an improvement in the lateral resolution, due to the low force atomic interaction between the silicon cantilever tip and the surface [33]. A robust AFM head that can track the cantilever tip against the workpiece surface with a constant force of $0.1 \mu \mathrm{N}$ has been developed for on-machine measurement. The pre-loaded PZT actuator for servo-controlling the AFM cantilever had a stiffness of $100 \mathrm{~N} / \mu \mathrm{m}$ and a stroke of $53 \mu \mathrm{m}$. The high stiffness of the PZT actuator made it possible to mount the scale of a linear encoder with a resolution of $0.5 \mathrm{~nm}$ together with the AFM cantilever [60]. The high level of robustness of the linear encoder to electromagnetic noise was important for use of the AFM-head on a diamond turning machine for micro-structured surface measurement (Fig. 23). A spiral scanning path was generated by the spindle and the X-slide. Similar on-machine AFM measurements have been carried out for the 3D cutting edge profile of diamond tools [104].

3.2.1.2. Noncontact-type probes. Although a noncontact probe is sensitive to surface properties, which is its biggest weakness for on-machine surface metrology, it has the advantage of making relatively fast measurement without damaging the surface. Capacitive and laser triangulation sensors are the two most well-used noncontact-type probes for on-machine surface metrology. The sensor technologies for both types of probe are well established and commercial products are provided by a number of sensor manufacturers.

A capacitive sensor can reach sub-nanometric vertical resolution over a range of the order of $100 \mu \mathrm{m}$ [65]. It can only measure flat or nearly flat surfaces and is limited to measurement of slowly varying surface form deviations, such as roundness, straightness and flatness. In addition, since the measurement range and the working distance are small, parallelism between the sensor scan axis and the workpiece surface must be carefully aligned to keep the interval variation between the probe end and the surface within the measurement range and to avoid possible collision. In contrast, a laser triangulation sensor, as an optical sensor, has a longer range and a much larger working distance, making the alignment of the probe on the machine tool easier. However, similar to a capacitance sensor, a specular laser triangulation sensor can only measure flat or nearly flat surfaces [103,127], although some designs can minimise the influence of the slope angle of the surface $[66,183]$. Moreover, since the laser beam is incident onto the surface with a large angle of incidence, the lateral position of the light spot on the surface changes with the displacement in the height direction, which is an uncertainty 
Table 4

Commercially available on-machine air bearing probes.

\begin{tabular}{|c|c|c|c|}
\hline & Lion precision $[150]$ & Moore nanotech [171] & $\begin{array}{l}\text { Toshiba machine } \\
\text { [227] }\end{array}$ \\
\hline $\begin{array}{l}\text { Force mechanism, } \\
\text { shaft bearing, }\end{array}$ & $\begin{array}{l}\text { Air pressure, } \\
\text { air bearing, }\end{array}$ & $\begin{array}{l}\text { Air pressure, } \\
\text { air bearing, }\end{array}$ & $\begin{array}{l}\text { Air pressure, } \\
\text { air bearing, }\end{array}$ \\
\hline measuring force & $2 \mathrm{mN}$ & $1 \mathrm{mN}$ & $0.5 \mathrm{mN}$ \\
\hline Length transducer, & Capacitive sensor, $0.5 \mathrm{~mm}, 1 \mathrm{~nm}$ & LVDT, & Laser interferometer, $1 \mathrm{~mm}, 0.038 \mathrm{~nm}$ \\
\hline range, & & $1 \mathrm{~mm}$, & \\
\hline resolution & & $0.1 \mathrm{~nm}$ & \\
\hline Probe tip & $\mathrm{R}=3.175 \mathrm{~mm}$ diamond half sphere & $\mathrm{R}=1$ or $\mathrm{R}=2 \mathrm{~mm}$ ruby sphere & $\begin{array}{l}\mathrm{R}=0.25 \mathrm{~mm} \\
\text { ruby sphere }\end{array}$ \\
\hline Maximum surface angle & $\mathrm{N} / \mathrm{A}$ & $\pm 60^{\circ}$ & $\pm 72.5^{\circ}$ \\
\hline
\end{tabular}

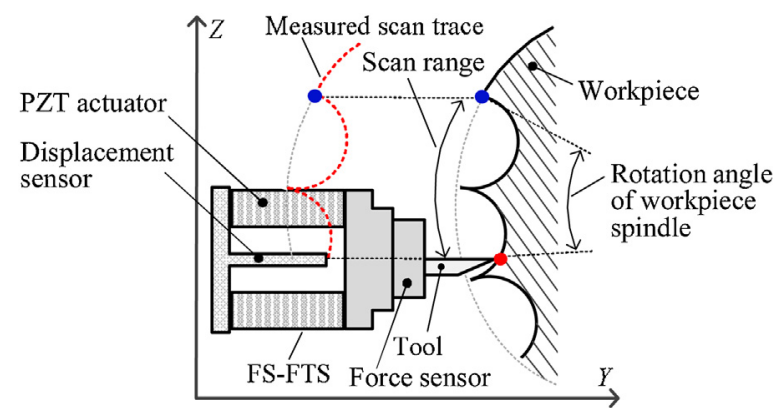

Fig. 22. FS-FTS used for on-machine measurement of micro-structured surface (modified from Ref. [62]).

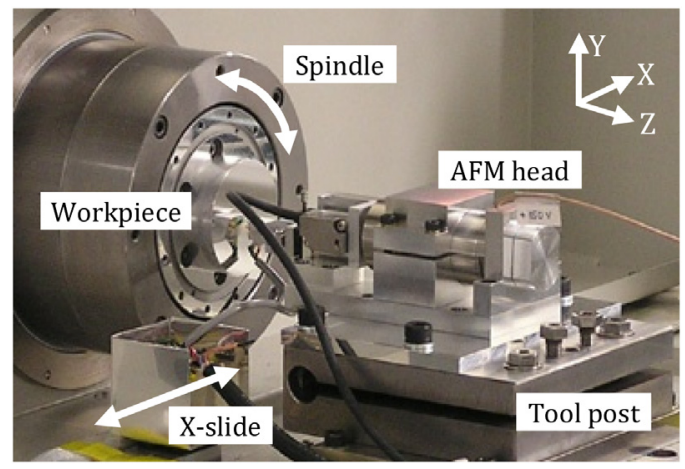

Fig. 23. An on-machine AFM head with a linear encoder [60].

factor for surface metrology. In contrast, a diffuse-type laser triangulation sensor for diffuse reflection surfaces has a vertical incident configuration and a large tolerance to surface angles, so is more suited for on-machine surface metrology [178].

Recent advances in CCD/CMOS technology and sub-pixel resolution algorithms have improved the performance of laser triangulation sensors in terms of measuring range, resolution and speed. A vertical resolution of $0.1 \mu \mathrm{m}$ can be achieved over a range of $1 \mathrm{~mm}$ and a bandwidth of $100 \mathrm{kHz}$. In particular, 2D laser triangulation, also referred to as laser line triangulation [166], has been developed for profile measurement of both specular and diffuse reflection surfaces. In such a 2D sensor, a line-shaped laser beam is incident onto the target surface to detect the height information, i.e. the profile along the illuminated surface line. This also significantly simplifies the scan and reduces the time for 3D surface topography measurement $[1,252]$. For example, a maximum lateral range of $180 \mathrm{~mm}$ can be detected by a long-range diffuse-type sensor [117]. The large working distance, up to several hundreds of millimetres, makes it possible to measure workpieces at elevated temperatures [77].

A confocal probe is another possible choice of an on-machine optical probe $[38,116]$. The insensitivity to the reflectivity of workpiece surface makes it possible to measure both specular and diffuse reflection surfaces. Keferstein et al. have integrated a chromatic confocal probe with a measurement range of $1 \mathrm{~mm}$ and a repeatability of $0.1 \mu \mathrm{m}$ into a grinding machine [114]. As the probe was mounted on to the grinding wheel head, the measurement range of the probe could be extended to the full stroke of the slide moving the wheel head, by synchronizing the probe signal with the linear encoder signal of the slide. New confocal technologies are being developed to further improve the robustness and the performance of confocal probes. As shown in Fig. 24, Takaya et al. have demonstrated the possibility of using a fluorescent confocal microscope to measure the surface of a tool covered with a cutting fluid layer based on sensing fluorescent emission from the cutting fluid excitation by focused laser light [221]. The method has been applied to measure submerged metallic micro-workpieces [167]. Chen et al. have showed a new chromatic confocal configuration by using a modelocked femtosecond laser source that can further improve the vertical resolution of the probe [23].

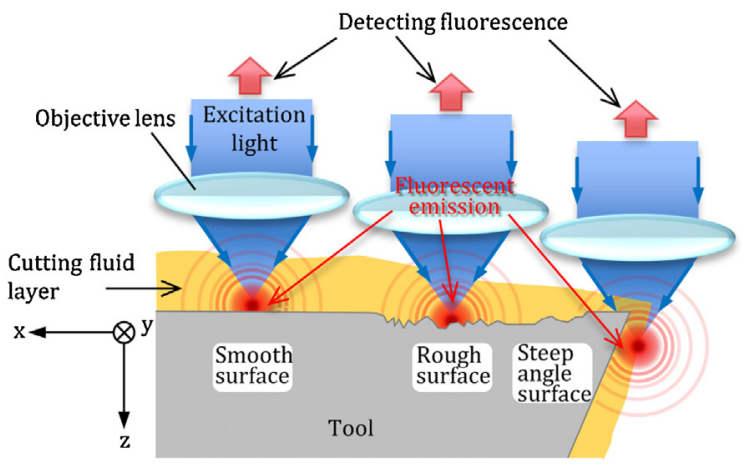

Fig. 24. A confocal probe for measurement of a tool's surface covered with a cutting fluid layer based on sensing fluorescent emission [221]

As a similar sensor technology, various types of autofocus sensors $[51,126,168,197]$ also have the capability for on-machine surface metrology. In addition to displacement sensors, it is possible to scan an optical angle/slope sensor for on-machine surface metrology. In the so-called laser autocollimation or laser deflectometry method, a thin laser beam is scanned over the workpiece surface to obtain the local slope of the surface at each scan position [42]. The surface topography can be obtained from a mathematic integration of the slope data. Since the variation between the sensor head and the workpiece surface does not influence the slope measurement, laser autocollimation is more robust to machine vibration and thermal drift [69]. On-machine measurement of microstructures can be made by using slope sensors with a focused laser beam [74]. The scanning electrostatic force microscope (EFM) is a promising tool for noncontact measurement of submicrometric structures [63], which are difficult for a capacitive sensor or an optical sensor due to their limited lateral resolutions. The tip-to-sample distance in EFM is on the order of $100 \mathrm{~nm}$ during the scanning, which is more than ten times larger than that in a scanning tunnelling microscope (STM) $[82,236]$ and is large enough to avoid collision of the tip with the sample surface. In addition, pneumatic sensors [83] and ultrasonic sensors [213] are other types of noncontact sensors for on-machine surface metrology. 
3.2.2. Error compensation and separation in machine tool integration

Several important sources of errors should be taken into consideration when integrating a probe into a machine tool for onmachine probe-scan surface metrology.

The first issue is the Abbe error. Fig. 25 shows a simple model of the integration of a probe on a rotary grinding machine. The probe is mounted on to the grinding wheel (tool) head to carry out the Zdirection measurement. The probe scan motion in the XY plane is made by the spindle and the $\mathrm{X}$-slide. If the measurement range of the probe is not enough to detect the surface height variation, the range can be extended by using the $Z$-slide of the machine to move the probe along the $Z$-axis. However, in this case, due to the large Abbe offset between the probe axis and the Z-axis, even a small tilt error motion of the Z-slide will cause a large Abbe error [65]. One way to compensate for the Abbe error is based on a measurement of the slide tilt error motion. A better solution is to select a probe with a large enough measurement range so that the use of the Zslide for the Z-direction measurement can be avoided [208].

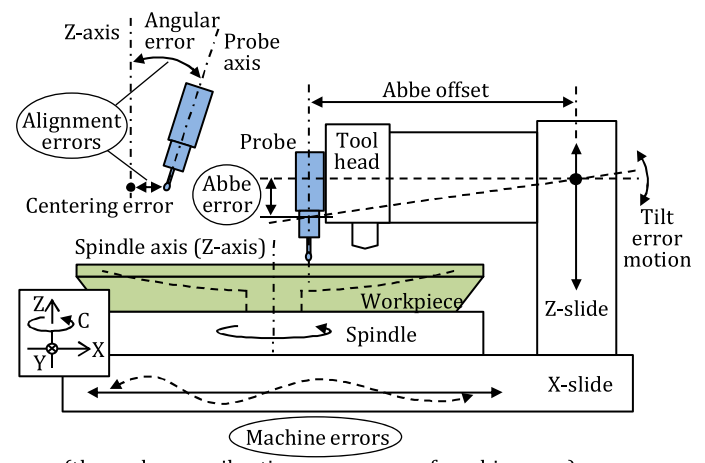

(thermal error, vibration, scan errors of machine axes)

Fig. 25. Error sources in integration of probe into machine tool.

The second issue is the accurate alignment/setting of a probe on a machine tool. Alignment error of the probe can be identified by using the probe to detect a precision sphere with an accurate location on the machine tool. Although this method is effective for many cases, it is subject to the availability of the precision reference sphere. There are some cases that do not satisfy this condition. For example, it is difficult to accurately mount a microsphere on the centre of the spindle of a diamond turning machine to allow centering alignment of the cantilever tip of an on-machine AFM with respect to the spindle centre. A micro-bump generated by a facing cut on the diamond turning machine, which was automatically located at the spindle centre, was employed for the centering alignment [60]. A simplified method, which does not require the use of a precision reference sphere and information of its accurate location, has also been proposed for alignment of a contact-type displacement probe [208]. In this method, the probe position with respect to the machine spindle can be obtained from the probe readings at four rotational positions of the reference ball.

The angular alignment error, which is the tilt angle of the probe axis with respect to the machine $Z$-axis, will cause a cosine error, which can be a large measurement uncertainty factor over a large range. As shown in Fig. 26, the orientation of an on-machine optical sensor is identified by utilizing an eccentric plate [114]. A simple and accurate method has also been demonstrated for on-machine identification of the angular alignment error of a contact-type displacement sensor [208].

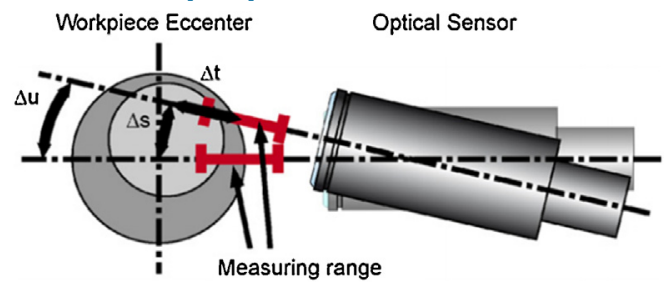

Fig. 26. Angular alignment error identification of an optical sensor [114].
In an on-machine probe-scan system, it is necessary to scan the probe with the machine axes. The motion errors (scan errors) of the machine axes along the probe axis [73], which are referred to as scan errors here for simplicity, will directly change the position of the probe with respect to the workpiece surface, resulting in a reading error in the probe output [145]. The repeatable and lowfrequency components of the scan errors can be compensated based on the measurement result of the errors that can be obtained prior to surface metrology. Compared with a full-field measurement system, it usually takes longer for the probe to scan over the workpiece surface. The measurement is thus more influenced by the machine errors caused by external disturbances, such as thermal error and vibration. The measurement and compensation methods for thermal errors of machine tools have been reviewed and updated in $[16,162]$. Thermal effects can be reduced by using low expansion materials, such as Zerodur or Invar, for critical parts of the metrology loop. Minimizing and controlling the heat flow and decreasing the thermal sensitivity of the machine are also possible methods for reducing the influence of thermal errors. The scan error of a machine axes used to scan the probe, such as the slide error and the spindle error, also has the same impact on the probe as the external disturbances.

It is more difficult to compensate for influences of machine vibration due to its random nature and wide bandwidth. The same can be said for the non-repeatable components of the machine scan errors. To compensate for such errors in on-machine surface texture measurement, it is possible to employ the traditional skiddatum method that has long been employed in mechanical surface profilers [241]. In this method, a skid with a large radius, which only senses the vibration and scan errors by spatially filtering out the surface texture information composed of higher spatialfrequency components, is used in combination with the stylus for error compensation. The same concept has been applied for a wide range STM $[124,206]$. As shown in Fig. 27, a more ideal skid-datum can be realized optically by coaxially combining a large reference beam and a focused measurement beam to detect the same part of the workpiece surface $[123,185]$.

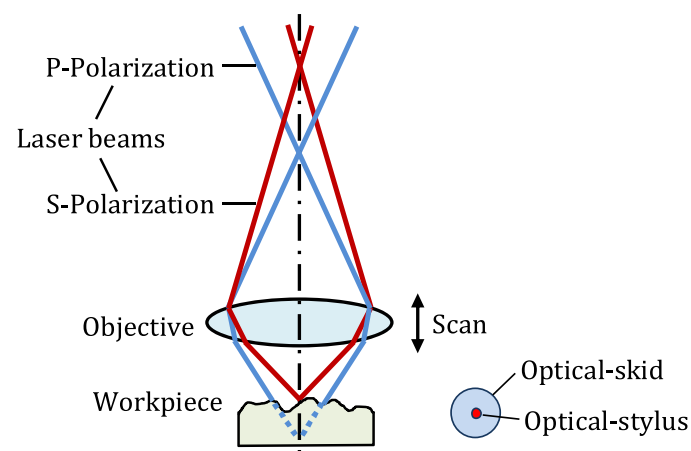

Fig. 27. Optical skid method for roughness measurement [123].

In on-machine surface form measurement, the multi-probe method, based on the concept of error-separation [46], is an effective way to compensate for both repeatable and nonrepeatable machine errors, including thermal errors and vibration. In a multi-probe method, multiple probes are employed to scan the workpiece surface simultaneously. A set of simultaneous equations are established using the outputs of the probes, each containing the surface profile information and the machine error information. The latter can be removed in a differential output based on the equations, from which the surface profile can be reconstructed. Since the invention of three displacement probe method, for roundness measurement by Aoki and Ozono [7], an extension to three-probe straightness measurement by Whitehouse [239], the three-probe method has been extensively developed for the measurement of roundness [113,170,209] and straightness $[41,143,238]$. Tanaka et al. simplified the system for straightness measurement by using two displacement probes, based on the 
assumption of small tilt error motion of the slide [223]. Kiyono and Gao have improved the profile reconstruction algorithm for the measurement of edge profiles [67,122]. Angle/slope sensors have been employed for construction of the multi-probe systems [64,79,121]. Recently, multi-probe methods have been applied for on-machine measurement of large rolls cut by drum roll lathes $[138,139]$.

It should be noted that the measurable spatial wavelength by a multi-probe system is limited by its probe arrangement. It is typically lower than that restricted by the probe size, which is the case in a single-probe system. This is because that certain harmonic components of the workpiece profile will be lost in the profile reconstruction process, which is referred to as the harmonic loss problem $[68,170,239]$. This is one of the significant shortcomings of multi-probe methods and must be treated carefully when designing the probe configuration. The number of lost harmonics can be reduced to some extent by employing asymmetric probe configurations and/or increasing the number of probes [256]. On the other hand, Gao et al. have proposed a mixed method to completely solve this problem by using multiple displacement and angle sensors [68] with the simplest configuration shown in Fig. 28 [70].

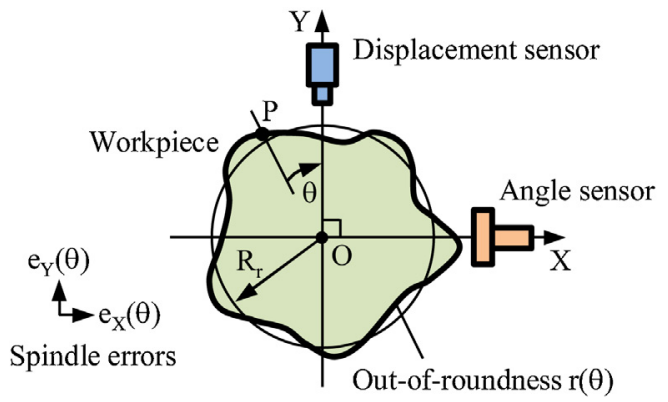

Fig. 28. The orthogonal mixed method using a pair of displacement and angle sensors for error separation in roundness measurement [70].

When a multi-probe method is employed for straightness measurement, the difference between the unknown zero-values of the probes (zero-difference) will introduce a parabolic error term in the reconstructed probe measurement, which is the largest error source for straightness measurement for long workpieces. This is an even more critical problem when a multi-probe system is used for flatness measurement where more probes are needed and it is necessary to align the probes on different lines of the workpiece surface except some special cases [64]. A self-calibration technique, in which two probe-units of the three-probe method are employed, has been proposed to accurately identify the zerodifference of probes for measurement of cylinder straightness [75]. The technique has been improved to measure and compensate for the variations of the zero-difference caused by thermal drift of the probe outputs during the scanning [71]. Another way to compensate for the influence of probe zero-difference, is to employ an external autocollimator to measure the tilt scan motion $[41,238]$.

Because a probe has a certain physical size, it becomes difficult to arrange multiple probes in a conventional multi-probe configuration to detect the same workpiece surface, if the workpiece is small. Although there has been research to construct multi-probe systems with probe intervals on the order of $100 \mu \mathrm{m}$ for small workpiece measurement [152,158], a more practical way is to establish an independent multi-probe system with a flat artefact for error-separation in measurement of the machine errors $[3,72,207]$. Since the multi-probe system is independent from the surface measurement probe, the restriction on the probe size can be avoided.

In some applications, the workpiece itself can be the most significant error source. For example, in-line form measurement of hot forged complex workpieces is challenged by the elevated temperature of the workpiece and special thermal shielding of sensors is required, as well as temperature-controlled metrology frames $[77,204]$.

\section{Calibration and traceability}

Traceability is defined in Ref. [105] as "the property of a measurement result whereby the result can be related to a reference through a documented unbroken chain of calibrations, each contributing to the measurement uncertainty" (see also Refs. $[43,88])$. For on-machine and in-process measurements, this implies that for traceability to be demonstrated, a number of calibration steps have to be taken. Calibration is defined as "an operation that, under specified conditions, in a first step, establishes a relation between the quantity values with measurement uncertainties provided by measurement standards and corresponding indications with associated measurement uncertainties and, in a second step, uses this information to establish a relation for obtaining a measurement result from an indication" $[18,105]$. More simply put, calibration is the comparison process needed at each stage of a traceability chain.

In the case of on-machine and in-process metrology, calibration is often given little explicit attention and/or neglected as a whole, as in a process under potentially harsh circumstances (environment, speed, etc.), it is difficult to measure or make a reference standard to use for comparison. The aim of both calibration and traceability is that, in the end, an uncertainty can be attributed to a measurement, or a quantified tolerance to a manufactured product.

As indicated in Section 2, in a manufacturing line or process, there is often a machine that has moving axes to move the machining element along the surface that has to be created or processed. Then there is the produced surface that can be measured directly as soon as it is processed, or at a later stage, still on machine, off machine in the same room, or off machine in a separate measurement room. For all these aspects, measurement systems and methods are available that have potentially unique properties when it comes to traceability and uncertainty estimation. In this section, an overview is given of available routes to traceability for the various aspects of on-machine and in-process measurement.

\subsection{Machine metrology traceability}

Calibration of machines, especially machine tools is reviewed in detail elsewhere [205], both for traditional machine tools [175] and for dedicated machines, such as those for the production of largescale optical surfaces [187] and roll-to-roll applications [133].

In these cases, the traceability is, directly or indirectly, provided by laser interferometer systems, that can be calibrated against a primary length standard [198]. In the direct cases, the displacements of the axes are directly measured by laser interferometer systems; in the indirect cases, the displacements of the axes are measured by linear scales, that have in turn been calibrated using laser interferometer systems [196]. In lithographic processes, there is no immediate requirement for in-process measurements, and the accuracy depends on the displacement measurements and the correction for geometric deviations [65]. However, in materialremoving processes, the surface of the final product is significantly affected by other aspects, e.g. straightness and squareness of the axes, temperature variations, tool shape and wear, and vibration. This is especially the case for machined surfaces, which is why additional on-machine and in-process surface measurements are needed and their traceability must be considered separately.

\subsection{Machining element traceability}

An important factor that determines the condition of a machined surface is the shape or structure of the machining element, i.e. the element that shapes the surface and determines the surface state in terms of form and texture. An example is the 
monitoring of tool wear in turning. This can be monitored onmachine and in-process in various ways, e.g. by binocular vision [263], by knife-edge interferometry [106] or by acoustic emission sensors [9]. Grinding wheel wear has been monitored in-process by laser triangulation [13] and imaging [52]. Typically for these methods, little attention is paid to uncertainty and traceability. This is understandable as these methods are mainly used as process indicators and the process parameters are not easily connected to the resulting surface properties. In addition, the optical interaction with a machined surface is highly complex and non-linear, resulting in empirical methods being employed rather than deterministic models.

\subsection{Machined surface metrology traceability}

As it is the manufactured surface that ultimately matters, the traceability of the metrology used for monitoring and/or measuring the surface directly is most relevant. In this section, the traceability and calibration considerations for three typical and common surface measurement parameters will be discussed: texture, flatness and aspherical form.

\subsubsection{Traceability of texture measurements}

Surface texture is characterized in parameters that are standardized for the profile and areal cases in ISO 4287 [101] and ISO 25178-2 [99] respectively. Apart from the standardised parameter definitions, the filtering and probing conditions are essential, as given in ISO 4288 [102] and ISO 25178-3 [100]. Also, it is worth mentioning that the mechanical surface is the reference surface $[100,134]$.

These specification standards, requirements and interpretations mean that the traceability, and the uncertainty estimation, of texture (parameter) measurements can be complex [89,135]. Even in ideal environmental conditions on dedicated stand-alone measurement equipment, uncertainties of better that $1 \%$ are difficult to achieve [89], while a $5-10 \%$ uncertainty is already an optimistic estimate for optical profile measurements [226]. Methods and standards to calibrate surface texture measuring instruments are extensively described elsewhere [134].

Mechanical texture measurements can generally only be carried out when the process is temporally stopped and there is time for the probe to scan the surface without being disturbed. An example is given by Kwon and Fischer [130], who monitors tool wear by temporarily stopping the process and allowing a mechanical probe to perform a traditional texture measurement, see Fig. 29.

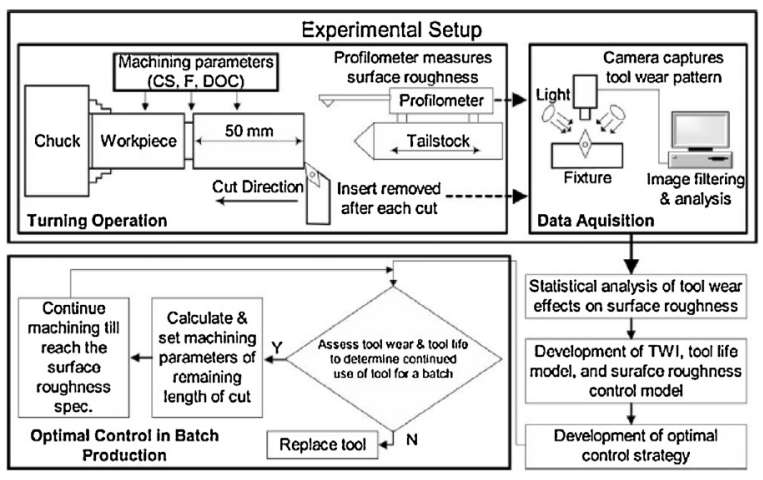

Fig. 29. On-machine surface metrology for roughness measurements as proposed by Kwon and Fischer [130].

In a process, an optical surface measuring system is often preferred as it can be much faster and the process does not need to be interrupted. Here, a distinction must be made between methods that measure the topography and derive texture parameters from the topography, and methods that measure an integral quantity. For the topography-measuring methods, all calibration methods and principles as described elsewhere apply [134], however, for the integral methods, the route to traceability is less straightforward.
A typical example of the latter can be found with Inasaki [97], who measures surface texture by measuring the reflectance of a laser beam by an optical fibre probe during a cylindrical grinding process (Fig. 30). The probe is calibrated off-line by a number of test surfaces having $R a$ values that are determined by a mechanical stylus instrument. Typically, cut-off lengths and uncertainties are not specified, however, the non-linear calibration curve suggests some $5 \%$ uncertainty.

Classical well-established methods of fast optical texture measurement are the measurement of either the specularly

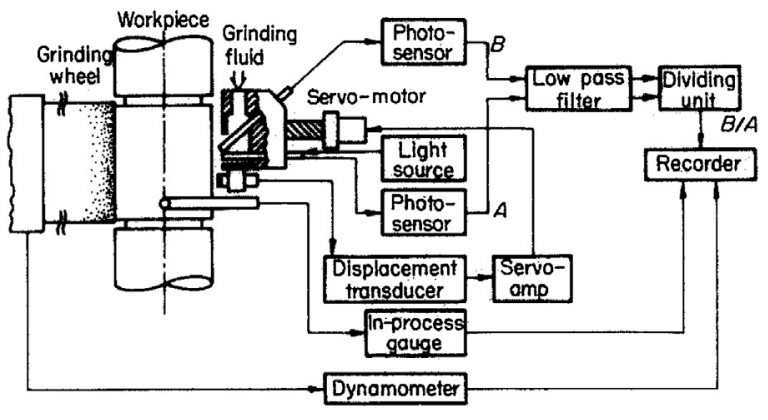

Fig. 30. In-process surface metrology as proposed by Inasaki [97].

reflected part of a (laser) beam directed at a surface, and/or the diffusely reflected part, also called total integrated scatter (TIS). These methods that were reviewed by Vorburger and Teague [231], are fundamentally limited to smooth surfaces (i.e. the features must be much smaller than the source wavelength) and have not essentially changed over the decades. All these methods have a traceability issue in the sense that they are essentially modelbased, and the texture parameters cannot be calculated from the definition. A common route to a limited form of traceability is the manufacturing of a range of surfaces with different textures; measure these off-line with established instruments, and take these as calibration references for the optical measurements that were taken during the manufacturing of these artefacts. In such a way, a calibration curve can be established that relates the texture to a scattering parameter, assuming that the manufacturing process varies with some linearity in the height and width of the texture peaks and valleys. This methodology can more generally be used for machined products and surfaces [242].

A typical related method is speckle correlation [189]. The surface is illuminated with coherent light at an angle using a laser and a single image is taken of the surface. The contrast in the image is directly related to the surface texture. A refinement of the method is in changing the angle or wavelength and correlating the images. The method can be calibrated using reference surfaces with calibrated texture parameters, and it claims to be able to determine $R a$ values up to $6 \mu \mathrm{m}$. Calibration curves suggest a reproducibility of about $10 \%$.

With related methods, such as image-based defect-detection methods, it can be even more difficult to relate to the concept of traceability and uncertainty [219].

\subsubsection{Traceability of nominally flat surface measurements}

The manufacture of traditional surface plates is carried out in an iterative process where the surface is measured off-machine, e.g. using electronic levels, after which it is machined according to the obtained flatness map [90]. The traceability and uncertainty of this method was evaluated in detail elsewhere [87]. A system that is more appropriate for in-process measurement for plates up to $200 \mathrm{~mm} \times 200 \mathrm{~mm}$, based on pattern projection, was proposed by Fan and Shiou [53]. In this case, a system calibration takes place using a gauge block, sine bar, and an overall comparison with a CMM measurement. For optical surfaces, measurement using a Fizeau interferometer, as illustrated in Fig. 9, is a logical choice. For on-machine and in-process measurement, it is advantageous if the measurement can be done using a single image. This can be carried 
out using the carrier-fringe technique introduced by Takeda [222], or by phase-shifting the interferograms in an instantaneous way; [14] see also Section 3.1.1.1. The measured flatness deviations can be considered as directly traceable to the metre definition if a HeNe laser is used as the light source [214]. Regarding the traceability to 'absolute flatness', several reversal techniques are available $[24,47]$. For less demanding applications, pattern projection methods can be used, as was done by Walecki et al. [232], who integrated a calibration platform in his set-up for high-throughput wafer processing for solar cell manufacturing.

\subsubsection{Traceability of aspheric surface measurements}

Rahman et al. [191] describes a CMM-like on-machine mechanical profile measuring system that is used on a grinding machine for aspherical surfaces. The workpiece can be measured when the process is temporarily stopped. Much attention is paid to monitoring the grinding wheel diameter and appropriately correcting the machine tool path. After production, the 'real profile is measured off-line using a profile measuring instrument. Suzuki et al. [218] developed a $45^{\circ}$ tilted on-machine measuring system for small optical workpieces. The uncertainty is estimated from the measurement of a sphere with a known radius, and from a comparison with a, hopefully calibrated, form measuring instrument. Xi et al. [244] has developed a correction method for the grinding wheel position, for grinding a $800 \mathrm{~mm}$ diameter aspheric mirror, reducing the profile error from $65 \mu \mathrm{m}$ to $8 \mu \mathrm{m}$. Also here, a sphere is used to confirm the obtained improvement.

\section{Data processing and feedback}

\subsection{Data flow}

Data flow (also called stream processing or reactive programming) is a software paradigm describing how data streams are processed using computing into useful information, e.g a measurement result. The central element of the concept is the data, which flows through several steps (Fig. 31). This model is naturally described by flowchart diagrams and allows for a simple description of parallel and sequential processes with focus on data. The flow of data from one processing step to the next and can split and merge down this stream.

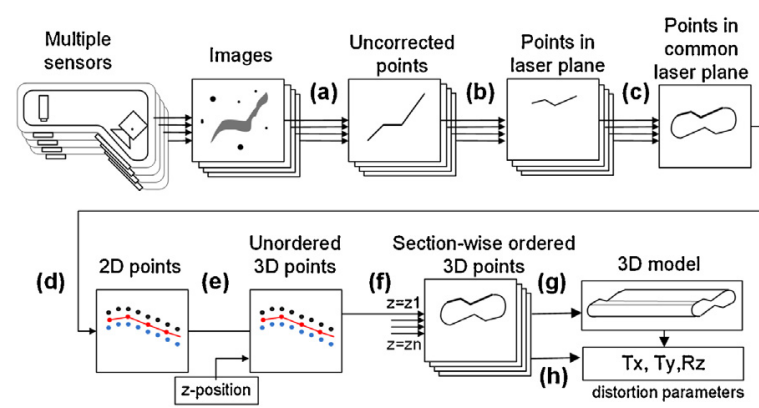

Fig. 31. Example of the high-level dataflow concept for a multi-sensor CMS. (a) laser line extraction in image coordinates; (b) lens distortion correction and transformation to laser plane coordinates; (c) 2D registration; (d) 2D data fusion; (e) 3D data fusion; (f) data sectioning in workpiece datums; (g) meshing; (h) extraction of application-specific parameters [203].

Data flow in manufacturing metrology begins with the readout of sensors, where physical quantities are converted into a digital representation. The data flow models how this representation is further processed to gain information, such as an indication of the measured quantity value, and in the right context, eventually leads to increased knowledge and added value [129,194].

As an example, the measuring process can be modeled by a data flow, i.e. data flows through processes as partition, extraction, filtration, association, collection and construction [98]. In this sequential model, processes are applied on measured coordinates and/or other data structures that describe a geometry. Even if data processing is often not explicitly described in literature, it is always inherent to digital metrology systems. Actually, as in other domains, where numerical data processing is employed, its importance is growing since more data is available and adequate algorithms and computing power exist, e.g. big data analytics and machine learning.

An example of a fairly complex dataflow including data fusion, adjustment, filtration, etc. is described in Ref. [77]. They use eight light-sectioning sensors in a complementary setup [237] to measure complex shaped workpieces. A specific adjustment procedure to increase the system accuracy was developed, enabling the evaluation of multiple geometrical parameters and eventually achieving holistic form measurements [203].

In this system, the data flow is parallelized during the first steps, where coordinates in image coordinate systems are obtained by CCD sensors and on-camera FPGA (field-programmable gate array) processing, i.e. laser line coordinates are extracted from the image of each sensor on the camera (Fig. 31). Thus, in this example, dataflow is not only parallelized but also distributed over multiple distinct computing systems. After calibration information is applied and coordinates are converted to a metric system, measurement data is then fused and filtered to obtain a complete profile of a workpiece. Subsequently, each two consecutive sections are meshed together to obtain a 3D surface representation. Note that this last step is already executed while acquisition is in process. Moreover, it processes in a time-sliced manner, i.e. the next section can already be meshed into the 3D model, even if meshing of the previous contour is not yet finished. By this high degree of parallelization and high-speed sensors, over one million spatial coordinates can be processed per second [77].

Data flow and measurement data processing are not only supportive, but crucial for the resulting information, e.g. a measured quantity value. For example, the use of inappropriate filter parameters would result in distorted results and valuable information can be lost. If appropriate data processing is applied, digital processing is effective and enables an information gain that would not be possible by manual methods.

Most data processing is carried out in the digital domain nowadays. This allows evaluation of many data in an automated fashion in little time. Thus, digitalization leads to an increasing quantity of measurement data and to applicability of sophisticated data processing algorithms. Since the exponential increase of computing power per monetary unit can only be retained by parallelization of computation, also known as Moore's Law, future data processing for metrology systems will inevitably contain certain parallelized processes.

How geometry is described digitally or how measurement data is structured during the processing, e.g. in clear text or binary format, is extensively described in Ref. [262].

\subsection{Sampling strategies}

In a measurement scenario, the sampling strategy is one of the factors contributing to the measurement uncertainty, especially when the sampling location is sparse to save time, e.g. measuring with a touch-trigger probe on a CMM [32]. To obtain a balance of low measurement uncertainty and high measurement efficiency, an advanced sampling strategy is most desirable such as adaptive sampling according to different surface curvature [39]. ElKott and Veldhuis [40] proposed several non-uniform rational B-spline (NURBS) surface parameter-based algorithms for the measurement of freeform surfaces. NURBS parameters, surface patch size, and surface patch mean curvature are used as the criteria in the sampling process. Ainsworth et al. [4] presented a CAD-based approach for the planning of a CMM measurement path, which uses a recursive subdivision algorithm to sample the surfaces along with their isoparametric lines. Chord length, minimum sampling density, and surface parameterization are the criteria used to guide the process. The work presented by ElKott and Veldhuis [40] adopted the sampling of surface isoparametric curves, which are used to construct substitute geometry for the physical object. Both curvature change and accuracy of substitute geometry are used to determine the locations of the sampled curves. 
Although many of the off-machine sampling strategies are applicable for on-machine surface metrology by using CAD/CAM software to generation NC codes of the sampling path [173], it is important to plan the sampling strategy based on the machine tool configuration. For example, on a T-base three-axis diamond turning machine, it is efficient to employ the spiral scan/sampling strategy by synchronizing the motions of the $\mathrm{X}$ linear axis and the $\mathrm{C}$ spindle axis [60]. A similar strategy can be employed in a three-axis rotary surface grinding machine [208]. Liu et al. [151] utilized a sampling strategy for a 2D laser triangulation sensor on an ultra-precision polishing machine with three linear axes $(\mathrm{X}, \mathrm{Y}, \mathrm{Z})$, three rotational axes $(\mathrm{A}, \mathrm{B}, \mathrm{C})$ and a spindle axis $(\mathrm{H})$. As shown in Fig. 32, the scanning strategy consists of rotational motion of the $B$ axis and linear motions of the $X$, $Y$ and $Z$ axes. The $A$ axis has a fixed angle to ensure that the laser sensor is perpendicular to the $\mathrm{X}-\mathrm{Y}$ plane. The laser sensor is rotated around the $B$ axis and a scanning slice can be generated. The workpiece is moved along the $\mathrm{X}, \mathrm{Y}$ and $\mathrm{Z}$ axes, combined with the scanning of the $B$ axis. As a result, the whole surface of the workpiece can be scanned. In some cases, additional sensor motion axes can be added for specific scan/sampling strategies. Anderson and Burge developed a system by adding a rotary stage to swing-arm sensor for measurement of large-sized aspheric workpieces on a grinding/ polishing machine, where the axis of rotation of the arm passes through the centre of curvature of the workpiece [5]. A sensor is mounted at the end of the arm that swings along an arc line across the centre of the aspheric workpiece. By scanning the arc lines at different angular positions of the turntable of the grinding/polishing machine, a scanning pattern could be obtained in which the arc lines cross with each other. The crossing height information was employed to stitch the scans for reconstruction of the surface topography [216].

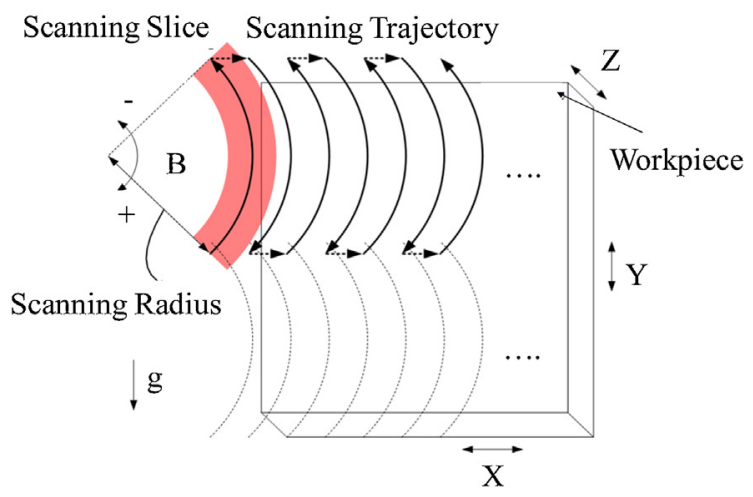

Fig. 32. Scanning strategy of the on-machine metrology [151].

\subsection{Interfaces}

For on-machine surface metrology, it is necessary to connect the elements of the measurement system, including the surface measuring probe/instrument, the personal computer (PC), the machine tool NC controller and the user with appropriate hardware, software and user interfaces, for acquisition of the surface measurement data and for feedback of the compensation data. The interfaces can be significantly different from those used for off-machine surface metrology due to the interaction with the machine tool and/or the NC controller.

Fig. 33 shows the interfaces in an NC controller integrated probe-scan system for workpiece setting and inspection [192]. After receiving the measurement command from the controller, the probe, which is stored in the tool magazine of the automatic tool changer (ATC), is mounted on the machine tool spindle for measurement of the workpiece surface. A wireless interface, either optical or radio, is employed for transmission of the signals between the probe and the controller through a receiver unit. For a touch trigger probe, the receiver is connected to the input of the controller for the high-speed skip function. Once the controller has received the triggered signal from the probe, the controller automatically captures the coordinates of the probe position via the encoders of the machine tool axes.
Renishaw has also developed a high-speed optical interface that processes data from the receiver and provides input/output communication with the machine tool for a contact probe in continuous-path mode [160,192]. On-machine macro software packages are installed and resident on the controller so that onmachine programming can be performed at the controller using traditional G-code, through a graphical user interface for acquisition of the measurement data and generation of the NC feedback data to the process control. Table 5 shows the specifications of commercial wireless interfaces for on-machine probes [192].

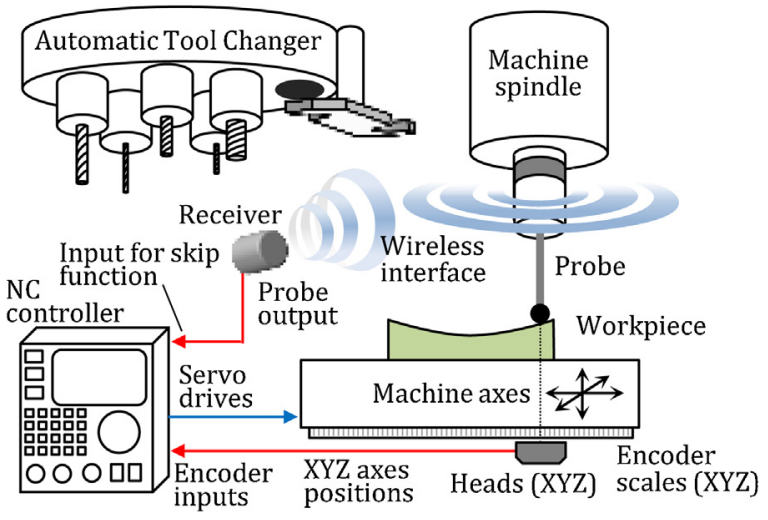

Fig. 33. Interfaces in an NC controller integrated probe-scan system.

Table 5

Wireless interfaces for on-machine probes [192].

\begin{tabular}{ll}
\hline Types & Specifications \\
\hline Infrared & Infrared light source. \\
& $360^{\circ}$ transmission envelop with a torus shape. \\
& $9 \mathrm{~m}$ maximum transmission range. \\
& Robust to electronic noise. \\
& Line-of-sight between probe and receiver is required. \\
& $2.4 \mathrm{GHz}$ radio wave source. \\
Radio & Frequency hopping spread spectrum (FHSS) transmission. \\
& $\begin{array}{l}\text { Negligible interference from other radio sources. } \\
\end{array}$ \\
& Suitable for large machines where line-of-sight \\
& between probe and receiver is not possible
\end{tabular}

It is often necessary to employ a PC which has better flexibility in data acquisition and processing for user-specific on-machine measurement tasks. It used to be a challenge to transfer the data of machine axis positions to a PC, since the electronics and hardware interfaces of a machine tool, including those of the encoders, are often not open for users to access [151]. Fig. 34 shows the interfaces connecting a PC and an ultra-precision grinding machine in a customized system by Olympus for on-machine surface metrology of endoscope optics [174]. With the assistance from the machine tool manufacturer, a signal interpolator with a 32 bit digital output was added between the encoder read head and the encoder serial interface of the NC controller for each of the X, Y and Z-machine axes to receive the sinusoidal voltage output signals of the encoder. A digital I/O board was employed as the interface connecting the interpolator and the PC. The surface form data were analyzed in the PC by using Windowsbased CAD/CAM software packages to produce the error compensation data. The compensation data were then fed back to the NC controller via a serial RS-232C interface, which is one of the standard interfaces of NC controllers, to carry out compensation machining by direct numerical control (DNC) [10,112]. In Fig. 34, since the air bearing probe had a linear encoder as the length measurement transducer, the same interpolator was employed to connect it with the PC. Similar to an off-machine system, FPGA, digital signal processor (DSP) and programming logic controllers (PLCS) can be employed to improve the processing speed of the interfaces between the probe, the PC and the machine tool encoder outputs $[153,227]$. 


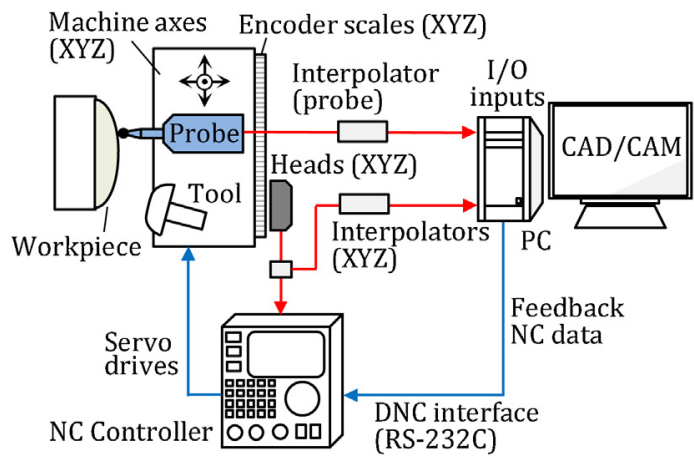

Fig. 34. Interfaces in a PC-based on-machine surface metrology system (modified from Ref. [174]).

Recently, with the development of open controller architecture (Open CNC) [190], it has become an easy and general operation for a PC to access the NC controller for obtaining machine axis positions and for uploading NC data in a large variety of user-specific applications $[11,86,95,193,230]$. Software interfaces, such as application programing interfaces, are provided by controller vendors for this purpose [57]. The standard hardware interfaces equipped in a NC controller for communication with a PC include, not only point-topoint interfaces such as RS-232C, optical fiber and USB, but also the Ethernet network interface [57,112]. More sensors and measuring instruments for surface metrology, such as laser displacement sensors [116,117] and full-field 3D systems [115,118], are now equipped with Ethernet interface in responding to the requirements of industrial Internet of Things (IoT). In an industrial Ethernet network as shown in Fig. 35 the hardware connections and software communications between machine tools, PCs and sensors/instruments can be seamlessly realized through the Ethernet interfaces. This will expand the flexibility and possibility of on-machine surface metrology for future manufacturing.

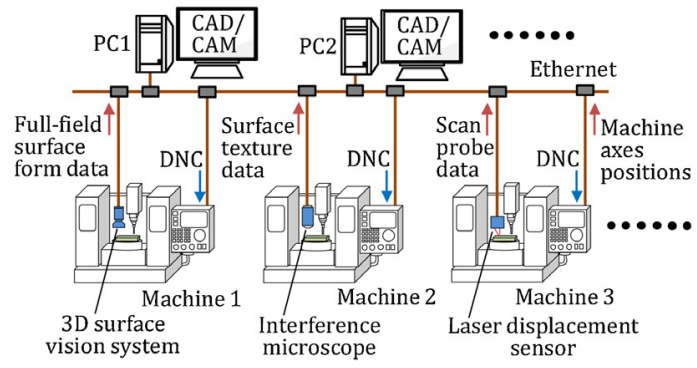

Fig. 35. Ethernet interfaces for next generation on-machine surface metrology network.

\subsection{Data analysis and modelling}

Analysis of the measured data is carried out to extract feedback information to correct the machined workpiece on machine, and/ or to control the manufacturing key-characteristics using statistical process control (SPC) techniques on machine. Fig. 36 summarizes the needs of on-machine measurements.

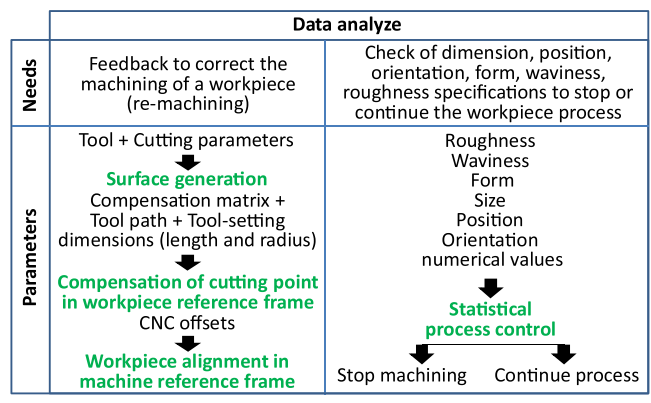

Fig. 36. Data analysis for on-machine surface metrology.

\subsubsection{Data analysis}

The aim of on-machine surface metrology is to furnish measured data to derive fine-machining parameters for compensation machining the workpiece. Therefore, this feedback needs parameters that can be adjusted in value. The adjustable parameters can be merged according to their effects on compensation machining. Table 6 summarizes the links between the finemachining parameters and the workpiece errors [225].

\section{Table 6}

Link between machining parameters and workpiece errors.

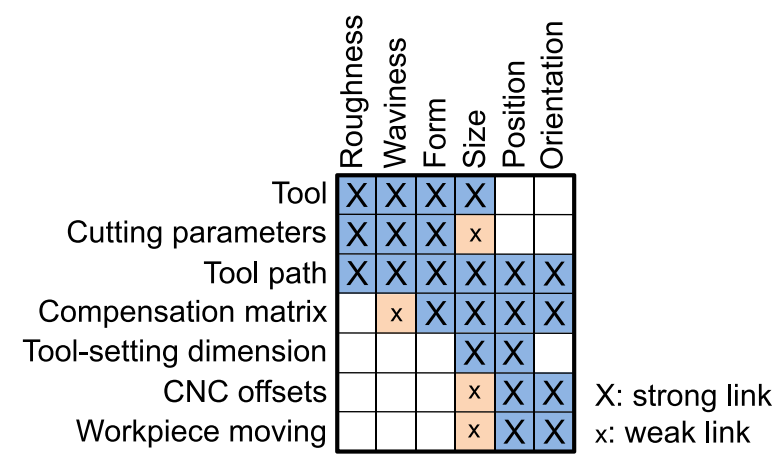

As shown in Fig. 36, on-machine measurement should be used to check, in-line, manufacturing key-characteristics (roughness, waviness, form, size, position, orientation or others). Generally, statistical process control (SPC) software is employed to do this task [155]. After the end of machining on the machine-tool, manufacturing key-characteristics of the workpiece are measured to check if the workpiece continues in the process or if the workpiece is rejected from the production. These key characteristics are derived from the surface deviation.

\subsubsection{Deviation calculations}

To derive the shape deviations, a model and a set of measures are necessary [217]. Moreover, optimization methods are used to approximate the deviations between the model and the manufactured surface. Mathematical methods used for this treatment, are detailed and summarized in numerous papers (least-squares method, maximum inscribed elements and minimum circumscribed element, minimum zone) $[6,111,149]$. The model can either represent the nominal surface (geometric objective expected to satisfy a user function) or model the surface with systematic defects expected during manufacturing (form defect, waviness, etc.). The first set of models are used to check the surface or geometrical specifications. This checking operation can be done including the uncertainties. The second is, generally, employed to give information for compensation machining the workpiece [8,10,234]. Fig. 37 summarizes these two sets of models (Nominal model, Adaptive model). The nominal model can be specified by an analytical equation in the case of a simple shape or by a set of equations for a complex shape described in a discrete manner. In addition, the latter modelling is used when the specification models come from a CAD system.

\begin{tabular}{|l|}
\hline $\begin{array}{c}\text { Local deviation } \\
\text { Roughness Waviness }\end{array}$ \\
Nominal models \\
Parametric model (Bezier, B-spline, Coons, etc) \\
\hline Delaunay triangulation, structured tessellation surface \\
\hline Adaptive models \\
Discrete Fourier, Cosines Transform, Discrete Modal Decomposition \\
\hline \hline
\end{tabular}

Fig. 37. Link deviations and models. 
These analytical models include of a set of parameters describing an elementary geometric deviation. The deviation description of the workpiece machined by the model will be more realistic if the number of its parameters is increased. The optimization residuals give an indication of the description quality of the real surface. The latter makes it possible to derive the association uncertainties of the model at the measured points [157]. Another way is the use of surfaces created from curves (B-spline, NURBS) $[30,81]$ or surfaces modeled by poles (Bezier, Coons, etc.) [58]. An artefact standard used for data exchange between software in industry allows the description of a freeform surface using B-spline paths. When the model becomes complex in size (data) or geometry, it is possible to choose a discrete model. In this case, Delaunay triangulation and structured tessellation surface methods can be used. The STL file format can be used to describe the nominal model with a geometrical approximation [12]. The best fit of this discrete model to the set of measured points needs segmentation [202], registration of 3D point clouds [237] and alignment methods [37]. The most used alignment method is iterative closest point. These nominal models can take into account the position and orientation deviations and the intrinsic deviation and the local deviations. As shown in Fig. 37, the discrete models are able to model the local deviation of the real surface using a small part of the discrete element. The limitations of parametric or analytical models is correlated to their mathematical complexity and their difficulty to filter the measured data for local deviations [137]. This impediment can be overcome by the use of adaptive models. Eigen shape basis sets were proposed to take into account the form deviations of the surface [58].

It is also possible to use multi-scale approaches based on discrete Fourier equations. Theses complete the description of the surface with local deviations, such as undulations and roughness. A discrete cosine transform method was proposed to model the surface deviations. This is the sum of cosine functions, where each term has a specific frequency. This description is based on independent basis vectors [111].

In the same way, discrete modal decomposition (DMD) decomposes a signal (measured set of points) within a spectral basis built from Eigen modes. The numerical solution of the differential equation of an element vibration gives the modes' vector space. The set of point coordinates is projected on this vector space $Q$. The contribution of each vector $Q_{i}$ is computed by the Moore-Penrose method [131].

\subsection{Feedback to compensation machining}

It is possible to apply real-time feedback with the results of onmachine surface metrology to compensate the machining process if the measurement is carried out under an in-process condition. Fig. 38 shows a simple model of real-time feedback in 2D cutting [229]. The sensor output detecting the machined area of the surface is employed to control the depth-of-cut for real-time compensation of the influence of machine errors. A similar concept has been practiced in milling, turning or boring operations with feedback from contact stylus [186], capacitive [76], eddy-current [50] and optical sensors [119]. The real-time feedback method has the advantage of high efficiency, since the measurement and compensation machining are carried out at the same time. However, compensation errors are unavoidable due to the interval between the positions of tool and on-machine probe as well as the delay caused by the limited bandwidth of the machine axis motions and the limited response speed of the feedback control system [229]. It is therefore sometimes necessary for the user to develop an additional fast tool servo system for the compensation machining as shown in Fig. 38. In addition, the availability of sensors for in-process surface metrology is an obstacle.

Alternatively, the feedback used with on-machine surface metrology for compensation machining is often carried out independently in intermediate steps. In such a non-real-time compensation approach, on-machine surface metrology is carried out off-process after the initial machining and the measurement result is fed back to
Real-time feedback

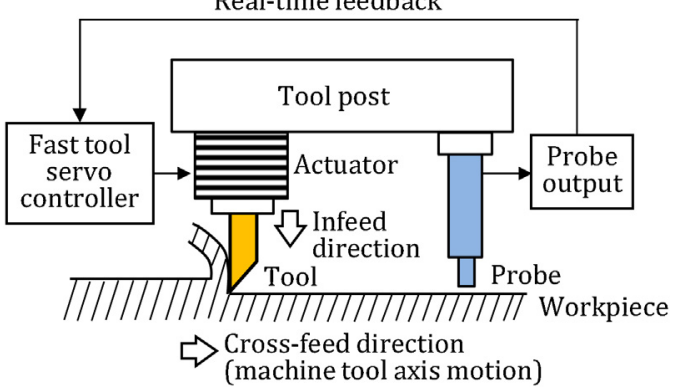

Fig. 38. Real-time feedback to compensation machining (modified from Ref. [229]).

compensation machining. The surface after compensation machining is then measured again to determine whether the next round of compensation machining is necessary or not. The combination of compensation machining and off-process measurement is repeated until the surface error is within the designed tolerance. Mounting, demounting and remounting operations for the on-machine probe are often associated because the probe is typically not permanently mounted on the machine tool due to the limited space and harsh environment during machining. The non-real-time compensation approach is more time-consuming on one hand but more practical on the other hand, compared with the real-time approach, because offprocess measurement is much easier to carry out. The feedback strategy of the on-machine measurement results in the compensation machining being more flexible, which can be carried out by (1) editing the program of the machine $\mathrm{NC}$ to generate a compensation tool path $[8,10,225]$, (2) changing the NC offset [184,233] and/or moving the workpiece [148] to adjust its position or orientation in the machining space, (3) modifying the tool setting to displace the cutting point of the tool path [184], or (4) adding a tool positioning system, such as a fast too servo, to control the depth-of-cut [61].

Fig. 39 shows the results of compensation grinding of a silicon carbide $(\mathrm{SiC})$ aspheric mirror of on a three-axis rotary surface grinding machine by feeding back to the machine NC controller [208], which is the most utilised feedback strategy. The mirror was designed to have a concave aspheric shape with a sag of approximately $35 \mathrm{~mm}$ over an $800 \mathrm{~mm}$ diameter. A grinding wheel path for compensation grinding was generated in the NC of the grinding machine, based on the feedback from the results of offprocess measurement by a contact-type displacement sensor, with a range of $60 \mathrm{~mm}$ associated with a scan motion along the radial direction of the mirror generated by the X-axis slide. A large machining error, up to approximately $45 \mu \mathrm{m}$, was confirmed at the outer area of the mirror after the initial grinding, due to the wear of the grinding wheel caused by the hard SiC material. The machining error was reduced to approximately $2 \mu \mathrm{m}$ after five repeated measurement and compensation machining operations. The alignment time for the re-mounted length sensor was less than 20 min with a fast alignment method [208]. A similar feedback strategy is used in grinding of aspheric moulds [19,174,218], cutting of freeform surfaces [259], machining of thin-walled blade workpieces [261], and many other processes.

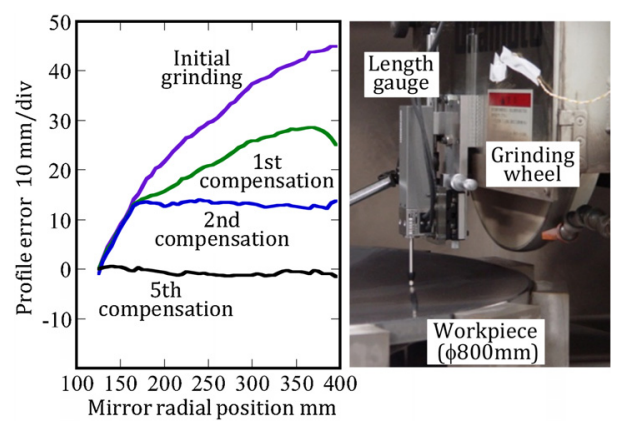

Fig. 39. On-machine measurement and compensation grinding of a $\mathrm{SiC}$ aspheric mirror workpiece through feedback to machine NC [208]. 
In Fig. 40, a different feedback strategy was employed on a fiveaxis cutting machine, where micro vee-grooves were cut on a retro-reflection mirror surface by fly cutting [257]. An air bearing probe was mounted on the B-axis to make off-process measurement of the surface form of the machined vee-grooves by moving the probe and the workpiece along the $\mathrm{X}$ and $\mathrm{Z}$ slides of the machine, respectively, from which the deviation of the vee-groove included angle could be identified. The measurement results were then fed back to align the tool position and orientation for the compensation cutting. The angular deviation was reduced from $1^{\circ}$ to $0.006^{\circ}$ after the compensation cutting.

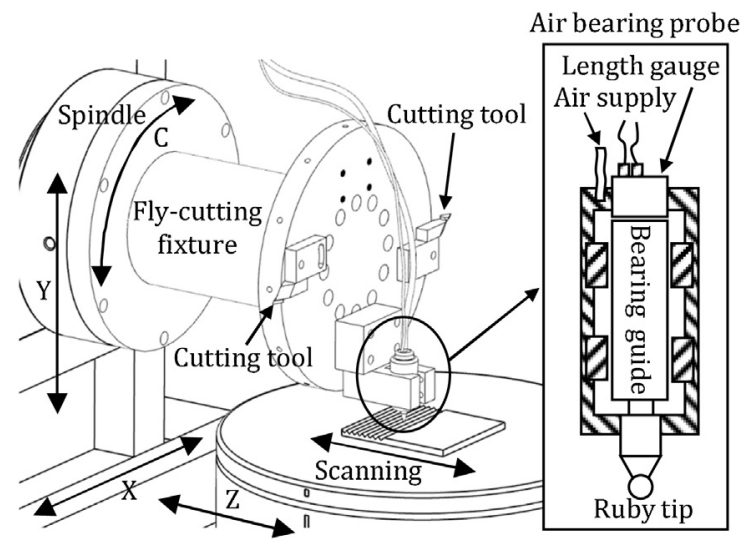

Fig. 40. On-machine measurement and compensation cutting of vee-grooves through feedback to adjustment of tool position and orientation [257].

Feedback of the measured information to compensation machining of micro-structures is a challenging task due to the critical requirement on the positioning accuracy of the tool. Chen et al. demonstrated the possibility of repairing defective microstructure elements on a large-area roll mould by using a FS-FTS [29]. The occurrence and the position of a defective element could be detected during the cutting process by the force sensor, and the sectional profile of the element could be characterized after the process, by using the tool itself as a force-controlled stylus probe. The defective element could then be accurately corrected in a subsequent repair cutting process through the feedback of the measured information to the FS-FTS and the machine tool NC controller for generating the repair tool path.

\section{Conclusions}

On-machine surface metrology plays an important role for precision manufacturing in a number of tasks. The first task is for initial alignment and/or positioning of a workpiece on the machine tool, which is the first step in a manufacturing process. The most straightforward task of on-machine surface metrology is to replace the conventional post-manufacturing inspection of the workpiece surface made on an off-machine and stand-alone surface measuring instrument. The on-machine results can also be employed for the task of compensation machining, and that of process and machine tool diagnosis. Each of the tasks has common and special requirements for both the measurement system and the data analysis/feedback process.

The measurement systems for on-machine surface metrology can be classified into full-field systems and probe-scan systems. Each have their own advantages and disadvantages. The former, which is usually an optical system, such as a surface interferometer, can accomplish the measurement in a short time without interactions with the machine tools and, therefore, with less influences from the machine kinematic errors. However, the measurable sizes and shapes of targets are limited and the system is susceptible to machine vibration and typically expensive. For these reasons, such a system is limited to some special manufacturing processes, such as large telescope mirror manufacturing. Significant advances have been achieved in onmachine 3D surface vision systems, with the progress in image sensing technologies. Especially, fringe reflection systems have demonstrated performance comparable to traditional interferometric systems, while being more cost-effective and robust to environment disturbances. It should be noted that the accuracy of a 3D surface vision system is largely determined by the calibration of the system. Development of accurate and effective on-machine calibration technologies of such systems remains as an important part of future work for traceable and more accurately manufactured workpieces.

Meanwhile, a probe-scan system, which is composed of a measuring probe and the associated scan motions provided by the axes of machine tools, does not have a limitation in measuring range and is, therefore, adaptable to the workpiece size. A variety of probes, either contact or noncontact, can be selected for measurement of different workpiece shapes and materials. Onmachine touch probe systems have become common accessories in a wide variety of precision machine tools from surface/cylinder grinding machines to multi-axis machining centres. A similar trend has been observed with on-machine air bearing probes, which are commercially available for ultra-precision grinding/cutting of optical surfaces/moulds of aspheric lenses and freeform optics. Although on-machine probe-scan systems are dominated by contact-type probes, the use of noncontact-type probes, especially laser triangulation sensors, is also increasing. The unique capability of a 2D laser triangulation sensor for measurement of a sectional profile of a workpiece surface, without moving a machine axis, is expected to further expand the applications in onmachine surface metrology. Compared with a full-field system, a probe-scan system is more influenced by machine errors, including both dynamic and kinematic error components. Abbe errors and probe alignment errors are also critical influence factors for the onmachine measurement results. Compensation of these errors is, therefore, important for assurance of the accuracy of the system.

Establishment of traceability for on-machine surface metrology is an essential task for assurance of the measurement reliability and a key issue for extending the applications of on-machine surface metrology in to precision manufacturing industries. Artefact-based calibration and traceability is a common way to achieve this. Data processing, including sampling strategy, data acquisition and analysis, is another important part of on-machine surface metrology, especially for feedback of the measurement data to the compensation machining process.

As one of the future trends in on-machine surface metrology, continuous progress in sensor technologies is expected to improve the robustness and reduce the cost of on-machine measuring instruments. More applications of on-machine surface metrology are also expected in precision manufacturing industries, i. e. for compensation machining. In the near future, on-machine surface metrology has the potential to become an essential part of a precision manufacturing process as well as a common function of a machine tool. Most importantly, with the advancement in industrial Ethernet and wireless interfaces, on-machine surface metrology will become an IoT-based activity to play a fundamental role in future manufacturing. To realize these goals, comprehensive standardization work on both hardware, such as the mountings, interfaces and NC controllers, and software, such NC codes for sensor output acquisition, surface error analysis, embedded calibration methods and automatic compensation tool path generation, is essential.

\section{Acknowledgements}

The fruitful discussions and suggestions from many colleagues in CIRP STCs P and S are appreciated. H. Martin and X. Jiang of Huddersfield University read and commented on the manuscript. D.W. Kim of Arizona University, L.C. Chen of NTU, S. Shirakawa of Heidenhain KK, K. Taknaka and M. Fukuda of Toshiba Machine, M. Tano of JTEKT, Y. Nagaike of Olympus, K. Kamiya of Toyama 
Prefectural University, G. Chapman of Moore Nanotech, H. Ogawa of Enable KK, A. Archenti and K. Szipka of KTH, R. Mayer of Polytechnique Montreal, B. Philip of ETH Zurich, R. Sato of Kobe University, S. Ibaraki of Hiroshima University, H. Yamashita of Captain Industries, L. Asanuma of M \& J, K. Oi of Keyence, E. Saito of Renishaw KK, S. Nishikawa of DMG Mori, X.D Zhang of Tianjin University provided valuable information. W. Gao thanks the significant contribution from Y.L. Chen and the support from JSPS.

\section{References}

[1] Abe G, Aritoshi M, Tomita T, Shirase K (2011) Development of On-machine Measurement System Utilizing Line Laser Displacement Sensor. International Journal of Automation Technology 5(5):708-714.

[2] Acosta D, Albajez JA, Yagüe-Fabra JA, Velázquez J (2018) Verification of Machine Tools Using Multilateration and a Geometrical Approach. Nanomanufacturing and Metrology 1(1):39-44.

[3] Adachi M, Miki H, Nakai Y, Kawaguchi I (1990) Precision Profiling Method Insensitive to Vertical Vibrations. Journal of JSPE 56(1):140-145.

[4] Ainsworth I, Ristic M, Brujic D (2000) CAD-based Measurement Path Planning for Freeform Shapes using Contact Probes. The International Journal of Advanced Manufacturing Technology 16(1):23-31.

[5] Anderson DS, Burge JH (1995) Swing Arm Profilometry of Aspherics. Proceedings of SPIE 2536:169-179.

[6] Anthony GT, Anthony HM, Bittner B, Butler BP, Cox MG, Drieschne R, Harris PM (1996) Reference Software for Finding Chebyshev Best-fit Geometric Elements. Precision Engineering 19(1):28-36.

[7] Aoki Y, Ozaono S (1966) On a New Method of Roundness Measurement Based on the Three-point Method. Journal of JSPE 32(12):831-836.

[8] Azzam N, Chaves-Jacob J, Boukebbab S, Linares JM (2014) Adaptation of Machining Toolpath to Distorted Geometries: Application to Remove a Constant Thickness on Rough Casting Prosthesis. International Journal of Advanced Manufacturing Technology 72(5-8):1073-1083.

[9] Bhuiyan M, Choudhury I, Dahari M, Nukman Y, Dawal S (2016) Application of Acoustic Emission Sensor to Investigate the Frequency of Tool Wear and Plastic Deformation in Tool Condition Monitoring. Measurement 92:208-217.

[10] Biermann D, Krebs E, Sacharow A, Kersting P (2012) Using NC-path Deformation for Compensating Tool Deflections in Micromilling of Hardened Steel. Procedia CIRP 1:132-137.

[11] Blaser P, Pavliek F, Mori K, Mayr J, Weikert S, Wegener K (2017) Adaptive Learning Control for Thermal Error Compensation of 5-axis Machine Tools. Journal of Manufacturing Systems 44(2):302-309.

[12] Boukebbab S, Bouchenitfa H, Boughouas H, Linares JM (2007) Applied Iterative Closest Point Algorithm to Automated Inspection of Gear Box Tooth. Computers \& Industrial Engineering 52(1):162-173.

[13] Brinksmeier E, Werner F (1992) Monitoring of Grinding Wheel Wear. CIRP Annals - Manufacturing Technology 41(1):373-376.

[14] Brock N, Hayes J, Kimbrough B, Millerd J, North-Morris M, Novak M, Wyant JC (2005) Dynamic Interferometry. Proceedings of SPIE, . 5875:58750F.

[15] Brown CA, Hansen HN, Jiang X, Blateyron F, Berglund J, Senin N, Bartkowiak T, Dixon B, Goïc GL, Quinsat Y, Stemp WJ, Thompson MK, Ungar PS, Zahouani H (2018) Multiscale analyses and characterizations of surface topographies. CIRP Annals - Manufacturing Technology 67(2):839-862.

[16] Bryan J (1990) International Status of Thermal Error Research. CIRP Annals Manufacturing Technology 39(2):645-656.

[17] Burge JH, Kot LB, Martin HM, Zhao C, Zobrist T (2006) Alternate Surface Measurements for GMT Primary Mirror Segments. Proceedings of SPIE, . 6273: 62732T.

[18] Carmignato S (2015) Calibration. in Laperrière L, Reinhart G, (Eds.) CIRP Encyclopedia of Production Engineering, Springer Reference, Spring- er-Verlag, Berlin, Heidelberg.

[19] Chen FJ, Yin SH, Huang H, Ohmori H, Wang Y, Fan YF, Zhu YJ (2010) Profile Error Compensation in Ultra-precision Grinding of Aspheric Surfaces with On-machine Measurement. The International Journal of Machine Tools and Manufacture 50(5):480-486.

[20] Chen LC, Lin YS (2014) 3-D Micro Surface Profilometry Employing Novel Mirau-Based Lateral Scanning Interferometry. Measurement Science and Technology 25094004.

[21] Chen LC, Nguyen XL (2010) Dynamic 3D Surface Profilometry Using a Novel Colour Pattern Encoded with a Multiple Triangular Model. Measurement Science and Technology 21(5):054009.

[22] Chen LC, Yeh SL, Tapilouw AM, Lee KF (2012) In-situ Scanning White Light Interferometry Employing Dual-sensing Configuration and Active Fringelocking Strategy. International Journal of Nanomanufacturing 8:40-52.

[23] Chen XG, Nakamura T, Shimizu Y, Chen C, Chen YL, Matsukuma H, Gao W (2018) A Chromatic Confocal Probe with a Mode-Locked Femtosecond Laser Source. Optics and Laser Technology 103:359-366.

[24] Chen XG, Shimizu Xiong X, Chen YL, Gao W (2017) Self-calibration of Fizeau Interferometer and Planar Scale Gratings in Littrow Setup. Optics Express 25 (18):21567-21582

[25] Chen YL, Cai YD, Shimizu Y, Ito S, Gao W, Ju BF (2016) On-machine Measurement of Microtool Wear and Cutting Edge Chipping by using a Diamond Edge Artifact. Precision Engineering 43:462-467.

[26] Chen YL, Cai YD, Shimizu Y, Ito S, Gao W, Ju BF (2016) Ductile Cutting of Silicon Microstructures with Surface Inclination Measurement and Compensation by using a Force Sensor Integrated Single Point Diamond Tool. Journal of Micromechanics and Microengineering 26(2):025002.
[27] Chen YL, Niu Z, Matsuura D, Lee JC, Shimizu Y, Gao W, Oh JS, Park CH (2017) Implementation and Verification of a Four-probe Motion Error Measurement System for a Large-Scale Roll Lathe Used in Hybrid Manufacturing. Measurement Science and Technology 28(10):105004

[28] Chen YL, Shimizu Y, Cai Y, Wang S, Ito S, Ju BF, Gao W (2015) Self-evaluation of the Cutting Edge Contour of a Microdiamond Tool with a Force Sensor Integrated Fast Tool Servo on an Ultra-precision Lathe. International Journal of Advanced Manufacturing Technology 77(9-12):2257-2267.

[29] Chen YL, Wang S, Shimizu Y, Ito S, Gao W, Ju BF (2015) An In-process Measurement Method for Repair of Defective Microstructures by Using a Fast Tool Servo with a Force Sensor. Precision Engineering 39:134-142.

[30] Cheung CF, Li HF, Lee WB, To S, Kong LB (2007) An Integrated form Characterization Method for Measuring Ultra-precision Freeform Surfaces. International Journal of Machine Tools and Manufacture 47(1):81-91.

[31] Choi HJ, Trumper I, Dubin M, Zhao W, Kim DW (2017) Simultaneous Multisegmented Mirror Orientation Test System Using a Digital Aperture Based on Sheared Fourier Analysis. Optics Express 25(15):18152-18164.

[32] Choi W, Kurfess TR, Cagan J (1998) Sampling Uncertainty in Coordinate Measurement Data Analysis. Precision Engineering 22(3):153-163.

[33] Danzebrink HU, Koenders L, Wilkening G, Yacoot A, Kunzmann H (2006) Advances in Scanning Force Microscopy for Dimensional Metrology. CIRP Annals - Manufacturing Technology 55(2):841-878.

[34] Danzl R, Helmli F, Scherer S (2009) Focus Variation - A New Technology for High Resolution Optical 3D Surface Metrology. Proceedings of The 10th International Conference of the Slovenian Society for Non-destructive Testing Application of Contemporary Non-destructive Testing in Engineering, 484-491.

[35] Davis JM, Martin HM, Kim DW, Loeff AR, Kenagy KL, Sisk RW, Hagen JR (2015) Advances in Diamond Generating for 8.4 Meter Telescope Mirrors. Proceedings of SPIE, . 9633: 96330Y.

[36] De Chiffre L, Lonardo P, Trumpold H, Lucca DA, Goch G, Brown CA, Raja J, Hansen HN (2000) Quantitative Characterisation of Surface Texture. CIRP Annals - Manufacturing Technology 49(2):635-652.

[37] Diez Y, Marta J, Salvi J (2012) Hierarchical Normal Space Sampling to Speed up Point Cloud Coarse Matching. Pattern Recognition Letters 33(16):2127-2133.

[38] Du HL, Zhou ZZ, Sun ZQ, Ju BF, Xu S, Sun A (2017) Full Area Covered 3D Profile Measurement of Special-shaped Optics Based on a New Prototype Noncontact Profiler. Review of Scientific Instruments 88(6):065102.

[39] Edgeworth R, Wilhelm RG (1999) Adaptive Sampling for Coordinate Metrology. Precision Engineering 23(3):144-154.

[40] Elkott DF, Veldhuis SC (2005) Isoparametric Line Sampling for the Inspection Planning of Sculptured Surfaces. Computer-Aided Design 37(2):189-200.

[41] Elster C, Weingärtner I, Schulz M (2006) Coupled Distance Sensor Systems for High-Accuracy Topography Measurement: Accounting for Scanning Stage and Systematic Sensor Errors. Precision Engineering 30(1):32-38

[42] Ennos AE, Virdee MS (1982)High Accuracy Profile Measurement of Quasi-conical Mirror Surfaces by Laser Autocollimation. Precision Engineering 4(1):5-8.

[43] Estler WT (2016) Traceability. in Laperrière L, Reinhart G, (Eds.) CIRP Encyclopedia of Production Engineering, Springer Reference, Spring- er-Verlag, Berlin, Heidelberg.

[44] EstlerWT, Edmundson KL, Peggs GN, Parker DH(2002)Large-scale Metrology - An Update. CIRP Annals - Manufacturing Technology 51(2):587-609.

[45] Evans CJ, Bryan JB (1999) Structured, Textured or Engineered Surfaces. CIRP Annals - Manufacturing Technology 48(2):541-556.

[46] Evans CJ, Hocken RJ, Estler WT (1996) Self-Calibration: Reversal, Redundancy, Error Separation, and 'Absolute Testing'. CIRP Annals - Manufacturing Technology 45(2):617-634.

[47] Evans CJ, Kestner RN (1996) Test Optics Error Removal. Applied Optics 35 (7):1015-1021.

[48] Faber C, Kurz M, Röttinger C, Olesch E, Domingos D, Löwenstein A, Häusler G, Uhlmann E (2012) Two Approaches to use Phase Measuring Deflectometry in Ultra Precision Machine Tools. Proceedings of Euspen 12(2):84-87.

[49] Faber C, Olesch E, Krobot R, Häusler G (2012) Deflectometry Challenges Interferometry - The Competition Gets Tougher, Proceedings of SPIE8493: 84930R.

[50] Fan KC, Chao YH (1991) In-process Dimensional Control of the Workpiece During Turning. Precision Engineering 13(1):27-32.

[51] Fan KC, Chu CL, Mou JI (2001) Development of a Low-cost Autofocusing Probe for Profile Measurement. Measurement Science and Technology 12(12):2137-2146.

[52] Fan KC, Lee MZ, Mou JI (2002) On-line Non-contact System for Grinding Wheel Wear Measurement. The International Journal of Advanced Manufacturing Technology 19(1):14-22.

[53] Fan KC, Shiou FJ (1997) An Optical Flatness Measurement System for Medium-sized Surface Plates. Precision Engineering 21(2-3):102-112.

[54] Fang FZ, Xu FF (2018) Recent Advances in Micro/Nano-cutting: Effect of Tool Edge and Material Properties. Nanomanufacturing and Metrology 1(1):4-31.

[55] Fang FZ, Zhang XD, Gao W, Guo YB, Byne G, Hansen HN (2017) Nanomanufacturing-Perspective and Applications. CIRP Annals - Manufacturing Technology 66(2):683-705

[56] Fang FZ, Zhang XD, Weckenmann A, Zhang GX, Evans C (2013) Manufacturing and Measurement of Freeform Optics. CIRP Annals - Manufacturing Technology 62(2):823-846.

[57] FANUC (2018) Catalogue. FOCAS2 (FANUC Open CNC API Specification),

[58] Farin G (2014) Curves and Surfaces for Computer-aided Geometric Design: A Practical Guide, Elsevier.

[59] Gao W (2010) Precision Nanometrology-sensors and Measuring Systems for Precision Manufacturing, Springer.

[60] Gao W, Aoki J, Ju BF, Kiyono S (2007) Surface Profile Measurement of a Sinusoidal Grid Using an Atomic Force Microscope on a Diamond Turning Machine. Precision Engineering 31(3):304-309.

[61] Gao W, Araki T, Kiyono S, Okazaki Y, Yamanaka M (2003) Precision Nanofabrication and Evaluation of a Large Area Sinusoidal Grid Surface for a Surface Encoder. Precision Engineering 27(3):289-298. 
[62] Gao W, Chen YL, Lee KW, Noh YJ, Shimizu Y, Ito S (2013) Precision Tool Setting for Fabrication of a Microstructure Array. CIRP Annals - Manufacturing Technology 62(1):523-526.

[63] Gao W, Goto S, Hosobuchi K, Ito S, Shimizu Y (2012) A Noncontact Scanning Electrostatic Force Microscope for Surface Profile Measurement. CIRP Annals Manufacturing Technology 61(1):471-474

[64] Gao W, Huang PS, Yamada T, Kiyono S (2002) A Compact and Sensitive Twodimensional Angle Probe for Flatness Measurement of Large Silicon Wafers. Precision Engineering 26(4):396-404

[65] Gao W, Kim SW, Bosse H, Haitjema H, Chen YL, Lu XD, Knapp W, Weckenmann A, Estler WT, Kunzmann H (2015) Measurement Technologies for Precision Positioning. CIRP Annals - Manufacturing Technology 64(2):773-796.

[66] Gao W, Kiyono S (1997) Development of an Optical Probe for Profile Measurement of Mirror Surfaces. Optical Engineering 36(12):3360-3366.

[67] Gao W, Kiyono S (1997) On-machine Roundness Measurement of Cylindrical Workpieces by the Combined Three-point Method. Measurement 21(4):147-156.

[68] Gao W, Kiyono S, Nomura T (1996) A New Multiprobe Method of Roundnes Measurements. Precision Engineering 19(1):37-45.

[69] Gao W, Kiyono S, Satoh E (2002) Precision Measurement of Multi-degree-of freedom Spindle Errors using Two-dimensional Slope Sensors. CIRP Annals Manufacturing Technology 51(1):447-450.

[70] Gao W, Kiyono S, Sugawara T (1997) High-accuracy Roundness Measurement by a New Error Separation Method. Precision Engineering 21(2-3):123-133.

[71] Gao W, Lee JC, Arai Y, Park CH (2009) An Improved Three-probe Method for Precision Measurement of Straightness. Technisches Messen 76(5):259-265.

[72] Gao W, Shibuya A, Yoshikawa Y, Kiyono S, Park CH (2006) Separation of Scanning Error Motions for Surface Profile Measurement of Aspheric Micro Lens. International Journal of Manufacturing Research 1(3):267-282.

[73] Gao W, Tano M, Araki T, Kiyono S, Park CH (2007) Measurement and Compensation of Error Motions of a Diamond Turning Machine. Precision Engineering 31(3):310-316.

[74] Gao W, Tano M, Sato S, Kiyono S (2006) On-machine Measurement of a Cylindrical Surface with Sinusoidal Micro-structures by an Optical Slope Sensor. Precision Engineering 30(3):274-279.

[75] Gao W, Yokoyama J, Kojima H, Kiyono S (2002) Precision Measurement of Cylinder Straightness using a Scanning Multi-probe System. Precision Engineering 26(3):279-288.

[76] Garbini JL, Koh SP, Jorgensen JE, Ramulu M (1992) Surface Profile Measurement During Turning using Fringe-field Capacitive Profilometry. Transaction of the ASME 234(114):140-145.

[77] Ghiotti A, Schoch A, Salvadori A, Carmignato S, Savio E (2015) Enhancing the Accuracy of High-speed Laser Triangulation Measurement of Freeform Parts at Elevated Temperature. CIRP Annals - Manufacturing Technology 64(1):499-502.

[78] Giusti F, Santochi M, Tantussi G (1987) On-line Sensing of Flank and Crater Wear of Cutting Tools. CIRP Annals - Manufacturing Technology 36(1):41-44

[79] Glenn P (1990) Robust, Angstrom Level Circularity Profilometry. Proceedings of SPIE 1333:230-238.

[80] Goch G, Schmitt R, Patzelt S, Stürwald S, Tausendfreund A, et al (2013) In-situ and In-process Metrology for Optical Surfaces. in Brinksmeier E, (Ed.) Fabrication of Complex Optical Components., Springer

[81] Gohari H, Barari A (2016) A Quick Deviation Zone Fitting in Coordinate Metrology of NURBS Surfaces using Principle Component Analysis. Measurement 92:352-364.

[82] Goto S, Hosobuchi K, Gao W (2011) An Ultra-precision Scanning Tunneling Microscope Z-scanner for Surface Profile Measurement of Large Amplitude Micro-structures. Measurement Science and Technology 22(8):085101.

[83] Grandy D, Koshy P, Klocke F (2009) Pneumatic Non-contact Roughness Assessment of Moving Surfaces. CIRP Annals - Manufacturing Technology 58 (1):515-518.

[84] Graves LR, Smith GA, Apai D, Kim DW (2019) Precision Optics Manufacturing and Control for Next-generation Large Telescopes. Nanomanufacturing and Metrology 2(2):65-90.

[85] Groot P, Lega XC, Kramer J, Turzhitsky M(2002) Determination of Fringe Order in White-light Interference Microscopy. Applied Optics 41(22):4571-4578.

[86] Guiassa R, Mayer JRR (2011) Predictive Compliance Based Model for Compensation in Multi-Pass Milling by On-machine Probing. CIRP Annals Manufacturing Technology 60(1):391-394.

[87] Haitjema H (1992) Uncertainty Propagation in Surface Plate Measurements Proceedings of the 4th International Symposium on Dimensional Metrology in Production and quality control (ISMQC), 304-320.

[88] Haitjema H (2013) Measurement Uncertainty. in Laperrière L, Reinhart G, (Eds.) CIRP Encyclopedia of Production Engineering, Springer Reference, Springer-Verlag, Berlin, Heidelberg.

[89] Haitjema H (2015) Uncertainty in Measurement of Surface Topography. Surface Topography: Metrology and Properties 3(3):035004.

[90] Haitjema H, Meijer J (1993) Evaluation of Surface Plate Flatness Measurements. European Journal of Mechanical and Environmental Engineering 38(4):165-172.

[91] Häusler G, Faber C, Olesch E, Ettl S (2013) Deflectometry vs Interferometry Proceedings of SPIE 8788. 87881C.

[92] HEIDENHAIN (2018) Catalogue. Length Gauges,

[93] HEIDENHAIN (2018) Catalogue. Touch Probes for Machine Tools,

[94] Hocken RJ, Chakraborty N, Brown C (2005) Optical Metrology of Surfaces. CIRP Annals - Manufacturing Technology 54(2):169-183.

[95] Ibaraki S, Kimura Y, Nagai Y, Nishikawa S (2015) Formulation of Influence of Machine Geometric Errors on Five-axis On-machine Scanning Measurement by Using a Laser Displacement Sensor. Journal of Manufacturing Science and Engineering 137(2):021013.

[96] IMS (2018) Messsysteme GmbH Catalogue. Measuring Systems in Hot Strip Mills, .

[97] Inasaki I (1985) In-process Measurement of Surface Roughness During Cylindrical Grinding Process. Precision Engineering 7(2):73-76.
[98] ISO 17450-1 (2011) Geometrical Product Specifications (GPS) - General Concepts - Part 1: Model for Geometrical Specification and Verification.

[99] ISO 25178-2 (2012) Geometrical Product Specification (GPS) - Surface Texture Areal - Part 2: Terms, Definitions and Surface Parameters.

[100] ISO 25178-3 (2012) Geometrical Product Specification (GPS) - Surface Texture Areal - Part 3: Specification Operators.

[101] ISO 4287 (1997) Geometrical Product Specifications (GPS) - Surface texture: Profile method - Terms, Definitions and Surface Texture Parameters.

[102] ISO 4288 (1996) Geometrical Product Specification (GPS) - Surface Texture: Profile method - Rules and Procedures for the Assessment of Surface texture.

[103] Ito S, Matsuura D, Meguro T, Goto S, Shimizu Y, Gao W, Adachi S, Omiya K (2014) On-Machine form Measurement of High Precision Ceramics Parts by Using a Laser Displacement Sensor. Journal of Advanced Mechanical Design Systems and Manufacturing 8(4):14-00089.

[104] Jang SH, Asai T, Shimizu Y, Gao W (2012) Establishment of a Measuring Station on a Diamond Turning Machine for In-process Cutting Edge Inspection of Single Point Diamond Micro-tools. International Journal of Nanomanufacturing 8:106-122.

[105] JCGM 200:2012(E/F) (2012) International Vocabulary of Metrology - Basic and General Concepts and Associated Terms (VIM),, 3rd edn. Joint Committee for Guides in Metrology, (Accessed 28 December 2017)http://www.bipm.org.

[106] Jeon S, Stepanick CK, Zolfaghari AA, Lee C (2017) Knife-edge Interferometry for Cutting Tool Wear Monitoring. Precision Engineering 50:354-360.

[107] Jiang X (2011) In Situ Real-time Measurement for Micro-Structured Surfaces. CIRP Annals - Manufacturing Technology 60(1). 563-563.

[108] Jiang X, Gao F, Martin Williamson HJ, Li D (2018) On-machine Metrology in Hybrid Machining, Chapter 10 Academic Press (Elsevier).

[109] Jiang X, Wang K, Gao F, Muhamedsalih H (2010) Fast Surface Measurement using Wavelength Scanning Interferometry with Compensation of Environmental Noise. Applied Optics 49(15):2903-2909

[110] Jiang X, Wang K, Martin H (2006) Near Common-path Optical Fiber Interferometer for Potentially Fast On-line Micro/Nano Scale Surface Measurement. Optics Letters 31:3603-3605.

[111] Jiang X, Whitehouse DJ (2012) Technological Shifts in Surface Metrology. CIRP Annals - Manufacturing Technology 61(2):815-836

[112] Jokanović S (2016) Communication with CNC Machine through DNC Interface. Proceedings of International Symposium on Small-scale Intelligent Manufacturing Systems, 19-24.

[113] Kakino Y, Kitazawa J (1978) In situ Measurement of Cylindricity. CIRP Annals Manufacturing Technology 27(1):371-375.

[114] Keferstein CP, Honegger D, Thurnherr H, Gschwend B (2008) Process Monitoring in Non-circular Grinding with Optical Sensor. CIRP Annals - Manufacturing Technology 57(1):533-536.

[115] Keyence KK (2018) Catalogue. 3D Interference Measurement Sensor,

[116] Keyence KK (2018) Catalogue. Multicolor coaxial laser displacement sensor .

[117] Keyence KK (2018) Catalogue. Ultra-high Speed In-line Profilometer,

[118] Keyence KK (2018) Catalogue. 3D Vision System XR-HT15M,

[119] Kim K, Eman KF, Wu SM (1987) In-process Control of Cylindricity in Boring Operations. Journal of Engineering for Industry 109(4):291-296.

[120] Kino M, Kurita M (2012) Interferometric Testing for Off-axis Aspherical Mirrors with Computer-Generated Holograms. Applied Optics 51(19):4291-4297.

[121] Kiyono S, Asakawa Y, Inamoto M, Kamada O (1993) A Differential Laser Autocollimation Probe for On-machine Measurement. Precision Engineering 15(2):68-76.

[122] Kiyono S, Gao W (1994) Profile Measurement of Machined Surface with a New Differential Surface with a New Differential Method. Precision Engineering 16(3):212-218

[123] Kiyono S, Huang PS, Suzuki H (1989) Optical Skid Method for Surface Roughness Measurement. Journal of JSPE 55(8):1409-1414.

[124] Kiyono S, Suzuki H, Shan XC, Kamada O (1992) Development of a Scanning Tunneling Microscope for Surface Roughness Measurement. Journal of the Japan Society for Precision Engineering 58(9):1509-1514.

[125] Knauer M, Kaminski J, Hausler G (2004) Phase Measuring Deflectometry: A New Approach to Measure Specular Freeform Surfaces. Proceedings of Photonics Europe, 366-376.

[126] Kohno T, Ozawa N, Miyamoto K, Musha T (1988) High Precision Optical Surface Sensor. Applied Optics 27(1):103-108.

[127] Koike Y, Kono D, Matsubara A, Yamaji I (2010) In-situ Measurement by using a Measurement-fused Machining System. Journal of JSPE 76(8):945-949.

[128] Kong IB, Kim SW (1995) Portable Inspection of Precision Surfaces by Phaseshifting Interferometry with Automatic Suppression of Phase-shift Errors. Optical Engineering 34(5):1400-1404.

[129] Kunzmann H, Pfeifer T, Schmitt R, Schwenke H, Weckenmann A (2005) Productive Metrology - Adding Value to Manufacture. CIRP Annals Manufacturing Technology 54(2):155-168.

[130] Kwon Y, Fischer GW (2003) A Novel Approach to Quantifying Tool Wear and Tool Life Measurements for Optimal Tool Management. International Journal of Machine Tools and Manufacture 43(4):359-368.

[131] Le Goïc G, Bigerelle M, Samper S, Favrelière H, Pillet M (2016) Multiscale Roughness Analysis of Engineering Surfaces: A Comparison of Methods for the Investigation of Functional Correlations. Mechanical Systems and Signal Processing 66-67:437-457.

[132] Leach RK (2011) Optical Measurement of Surface Topography, Springer.

[133] Leach RK, Evans C, He L, Davies A, Duparré A, Henning A, Jones CJ, O’Connor D (2014) Open Questions in Surface Topography Measurement: A Roadmap. Surface Topography: Metrology and Properties 3(1):013001.

[134] Leach RK, Giusca CL, Haitjema H, Evans C, Jiang X (2015) Calibration and Verification of Areal Surface Texture Measuring Instruments. CIRP Annals Manufacturing Technology 64(2):797-813.

[135] Leach RK, Haitjema H, Giusca (2018) A Metrological Characteristics Approach to Uncertainty in Surface Metrology. in Osten W, (Ed.) Optical Inspection of Microsystems. 2nd edn. CRC Press, Boca Raton, USA. 
[136] Leach RK, Smith ST (2018) Basics of Precision Engineering, CRC Press.

[137] Lecompte J, Legoff O, Hascoet JY (2010) Technological form defects identification using discrete cosine transform method. The International Journal of Advanced Manufacturing Technology 51(9-12):1033-1044

[138] Lee JC, Gao W, Shimizu Y, Hwang J, Oh JS, Park CH (2012) Precision Measurement of Carriage Slide Motion Error of a Drum Roll Lathe. Precision Engineering 36(2):244-251.

[139] Lee JC, Shimizu Y, Gao W, Oh J, Park CH (2014) Precision Evaluation of Surface form Error of a Large-scale Roll Workpiece on a Drum Roll Lathe. Precision Engineering 38(4):839-848.

[140] Lee KW, Noh YJ, Arai Y, Shimizu Y, Gao W (2011) Precision Measurement of Micro-lens Profile by Using a Force-controlled Diamond Cutting Tool on an Ultra-precision Lathe. International Journal of Precision Technology 2(2):211-225.

[141] Lee KW, Noh YJ, Gao W, Arai Y, Shimizu Y, Tanaka K, Fukuta M, Kai Y (2011) Experimental Investigation of an Air-bearing Displacement Sensor for Onmachine Surface form Measurement of Micro-structures. International Journal of Precision Engineering and Manufacturing 12(4):671-678.

[142] Lei P, Zheng L (2017) An Automated In-situ Alignment Approach for Finish Machining Assembly Interfaces of Large-scale Components. Robotics and Computer-Integrated Manufacturing 46:130-143.

[143] Li CJ, Li SY, Yu JM (1996) High-resolution Error Separation Technique for Insitu Straightness Measurement of Machine Tools and Workpieces. Mechantronics 6(3):337-347.

[144] Li D, Cheung CF, Ren MJ, Zhou L, Zhao X (2014) Autostereoscopy-based threedimensional on-machine measuring system for micro-structured surfaces. Optics Express 22(21):25635-25650.

[145] Li D, Jiang X, Tong Z, Blunt L (2018) Kinematics Error Compensation for a Surface Measurement Probe on an Ultra-Precision Turning Machine. Micromachines 9(7):334.

[146] Li D, Tong Z, Jiang X, Blunt L, Gao F (2018) Calibration of an Interferometric On-machine Probing System on an Ultra-precision Turning Machine. Measurement 118:96-104.

[147] Li XH, Yamauchi T, Iwai H, Yamashita Y, Zhang HJ, Hiruma T (2006) Full-field Quantitative Phase Imaging by White-light Interferometry with Active Phase Stabilization and its Application to Biological Samples. Optics Letters 31 (12):1830-1832.

[148] Li Y, Liu C, Hao X, Gao JX, Maropoulos PG (2015) Responsive Fixture Design using Dynamic Product Inspection and Monitoring Technologies for the Precision Machining of Large-scale Aerospace Parts. CIRP Annals-Manufacturing Technology 64(1):173-176

[149] Linares JM, Goch G, Forbes A, Sprauel JM, Clément A, Haertig F, Gao W (2018) Modelling and Traceability for Computationally-intensive Precision Engineering and Metrology. CIRP Annals - Manufacturing Technology 67(2):815-838.

[150] Lion Precision (2018) Catalogue. Air-Bearing C-LVDT,

[151] Liu MY, Cheung CF, Whitehouse D, Cheng CH (2016) An Autonomous Multisensor in situ Metrology System for Enabling High Dynamic Range Measurement of 3D Surfaces on Precision Machine Tools. Measurement Science and Technology 27(11):115015.

[152] Liu SJ, Watanabe K, Chen X, Takahashi S, Takamasu K (2009) Profile Measurement of a Wide-area Resist Surface using a Multi-ball Cantilever System. Precision Engineering 32(1):50-55.

[153] Liu YT, Kuo YL, Yan DW (2017) System Integration for On-machine Measurement using a Capacitive LVDT-like Contact Sensor. Advances in Manufacturing 5(1):50-58.

[154] Lowman AE, Smith GA, Harrison L, West SC, Oh CJ (2018) Measurement of Large On-axis and Off-axis Mirrors using Software Configurable Optical Test System. Proceedings of SPIE 10706. 107061E.

[155] Mac Gregor JF, Kourti T (1995) Statistical Process Control of Multivariate Processes. Control Engineering Practice 3(3):403-414.

[156] Mahr GmbH (2018) Catalogue. Inductive Probe,

[157] Mailhe J, Linares JM, Sprauel JM, Bourdet P (2008) Geometrical Checking by Virtual Gauge, Including Measurement Uncertainties. CIRP Annals Manufacturing Technology 57(1):513-516.

[158] Makosch G, Drollinger B (1984) Surface Profile Measurement with a Scanning Differential Ac Interferometer. Applied Optics 23(24):4544-4553.

[159] Marsh BJ (2008) Laser Tracker Assisted Aircraft Machining and Assembly. SAE Technical Paper Series. http://dx.doi.org/10.4271/2008-01-2313.

[160] Marshall D, Ould J (2014) Development of High-speed On-machine 3D Scanning System. Proceedings of ICPE, 17-20.

[161] Martin HM, Burge JH, Miller SM, Smith BK, Zehnder R, Zhao C (2006) Manufacture of a $1.7 \mathrm{~m}$ Prototype of the GMT Primary Mirror Segments. Proceedings of SPIE 6273. 62730G.

[162] Mayr J, Jedrzejewski J, Uhlmann E, Alkan Donmez M, Knapp W, Hartiäg F, Wendt K, Moriwaki T, Shore P, Schmitt R, Brecher C, Würz T, Wegener K (2012) Thermal Issues in Machine Tools. CIRP Annals - Manufacturing Technology 61 (2):771-791

[163] McKeown PA (1987) The Role of Precision Engineering in Manufacturing of the Future. CIRP Annals - Manufacturing Technology 36(2):495-501.

[164] McKeown PA, Wills-Moren WJ, Read RF (1987) In-situ Metrology and Machine Based Interferometry for Shape Determination. Proceedings of SPIE 802:42-47.

[165] Mendikute A, Leizea I, Yagüe-Fabra J, Zatarain M (2018) Self-calibration Technique for On-machine Spindle-mounted Vision Systems. Measurement 113:71-78.

[166] Micro-Epsilon (2018) Catalogue. Laser Profile Sensors,

[167] Mikulewitsch M, Auerswald MM, von Freyberg A, Fischer A (2018) Geometry Measurement of Submerged Metallic Micro-parts using Confocal Fluorescence Microscopy. Nanomanufacturing and Metrology 1(3):171-179.

[168] Mitaka Kohki Co., Ltd (2018) Catalogue. Point Autofocus Probe 3D Measuring Instrument,

[169] Molleda J, Usamentiaga R, Garcia DF (2013) On-line Flatness Measurement in the Steelmaking Industry. Sensors 13(8):10245-10272.
[170] Moore D (1989) Design Considerations in Multiprobe Roundness Measurement. Journal of Physics E: Scientific Instruments 22(6):339-343.

[171] Moore Nanotechnology Systems, LLC (2018) Catalogue. Workpiece Error Compensations System.

[172] Muhamedsalih M, Blunt L, Martin H, Hamersma I, Elrawemi M, Gao F (2015) An Integrated Opto-mechanical Measurement System for In-process Defect Measurement on a Roll-to-roll Process. Laser Metrology and Machine Performance XI 99-107.

[173] Murase M, Nishida I, Sato R, Shirase K (2018) Automation of On-machine Measurement Based on 3D CAD Model of Product. Proceedings of International Symposium on Flexible Automation: S042,

[174] Nagaike Y, Nakamura Y, Ito Y, Gao W, Kuriyagawa T (2006) Ultra-precision Onmachine Measurement System for Aspheric Optical Elements. Journal of the Chinese Society of Mechanical Engineers 27(5):535-540.

[175] Nakamoto K, Takeuch Y (2017) Recent Advances in Multiaxis Control and Multitasking Machining. International Journal of Automation Technology 11 (2):140-154

[176] Nasrollahi V, Penchev P, Dimov S, Korner L, Leach R, Kim K (2017) Two-Side Laser Processing Method for Producing High Aspect Ratio Microholes. Journal of Micro and Nano-manufacturing 5(4):041006.

[177] Niranjan Prasad K, Ramamoorthy B (2001) Tool Wear Evaluation by Stereo Vision and Prediction by Artificial Neural Network. Journal of Materials Processing Technology 112(1):43-52.

[178] Nishikawa S, Ohno K, Mori M, Fujishima M (2014) Non-contact Type Onmachine Measurement System for Turbine Blade. Procedia CIRP 24:1-6.

[179] Noh YJ, Arai Y, Tano M, Gao W (2008) Fabrication of Large-area Micro-lens Arrays with Fast Tool Control. International Journal of Precision Engineering and Manufacturing 9(4):32-38.

[180] Nomura T, Miyashiro H, Kamiya K, Yoshikawa K, Tashiro H, Suzuki M, Usuki M, Kobayashi F (1993) Shape Measurement of Workpiece Surface with Zoneplate Interferometer During Machine Running. Precision Engineering 15 (2):86-92.

[181] Nomura T, Yoshikawa K, Tashiro H, Takeuchi I, Ozawa N, Okazaki Y, Suzuki M, Kobayashi F, Usuki M (1992) On-machine Shape Measurement of Workpiece Surface with Fizeau Interferometer. Precision Engineering 14(3):155-159.

[182] Oh CJ, Lowman AE, Smith GA, Su P, Huang R, Su T, Kim D, Zhao C, Zhou P, Burge $\mathrm{JH}$ (2016) Fabrication and Testing of $4.2 \mathrm{~m}$ Off-axis Aspheric Primary Mirror of Daniel K. Inouye Solar Telescope. Proceedings of SPIE 9912. 991200.

[183] Osawa S, Ito S, Shimizu Y, Jang S, Gao W, Fukuda T, Kato A, Kubota K (2012) Cutting Edge Height Measurement of a Rotary Cutting Tool by a Laser Displacement Sensor. Journal of Advanced Mechanical Design Systems and Manufacturing 6(6):815-828.

[184] Pairel É, Goldschmidt E, Adragna PA, Hernandez P, Pillet M (2011) The Pilot Dimensions Method: Reconciling Steering and Conformity in Workshops. International journal of production research 49(19):5943-5956.

[185] Pantzer D, Politch J, Ek L (1986) Heterodyn Profiling Instrument for the Angstrom Region. Applied Optics 25(22):4168-4172.

[186] Park CW, Eman KF, Wu SM (1988)An In-process Flatness Error Measurement and Compensatory Control System. Journal of Engineering for Industry 110:263-270.

[187] Peng XQ Dai YF, Li SY (2015) Nanometer Precision Fabrication for Large Scale Optical Surfaces. Journal of National University of Defense Technology 37(6):1-7.

[188] Perard D, Beyerer J (1997) Three-dimensional Measurement of Specular Freeform Surfaces with a Structured-lighting Reflection Technique. Proceedings of SPIE 3204:74-80.

[189] Persson U (2006) Surface Roughness Measurement on Machined Surfaces using Angular Speckle Correlation. Journal of Materials Processing Technology 180(1-3):233-238.

[190] Pritschow G, Altintas Y, Jovane F, Koren Y, Mitsuishi M, Takata S, Brussel HV, Weck M, Yamazaki K (2001) Open Controller Architecture - Past, Present and Future. CIRP Annals - Manufacturing Technology 50(2):463-470.

[191] Rahman S, Saleh MT, Lim HS, Son SM, Rahman M (2008) Development of an On-machine Profile Measurement System in ELID Grinding for Machining Aspheric Surface with Software Compensation. International Journal of Machine Tools and Manufacture 48(7-8):887-895.

[192] Renishaw plc (2018) Catalogue. Probing Systems for CNC Nachine Tools.

[193] Sato R, Shirase K (2018) Geometric Error Compensation of Five-axis Machining Centers Based on On-machine Workpiece Measurement. International Journal of Automation Technology 12(2):230-237.

[194] Savio E, De Chiffre L, Carmignato S, Meinertz J (2016) Economic Benefits of Metrology in Manufacturing. CIRP Annals - Manufacturing Technology 65 (1):495-498

[195] Savio E, De Chiffre L, Schmitt R (2007) Metrology of Freeform Shaped Parts. CIRP Annals - Manufacturing Technology 56(2):810-835.

[196] Sawabe M, Maeda F, Yamaryo Y, Simomura T, Saruki Y, Kubo T, Sakai H, Aoyagi S (2004) A New Vacuum Interferometric Comparator for Calibrating the Fine Linear Encoders and Scales. Precision Engineering 28(3):320-328.

[197] Sawano H, Takahashi M, Yoshioka H, Shinno H, Mitsui K (2011) On-machine Optical Surface Profile Measuring System for Nano-machining. International Journal of Automation Technology 5(3):369-376.

[198] Schellekens H, Koning J, Veenstra PC (1982) Accuracy of Commercially Available Laser Measurement Systems. CIRP Annals - Manufacturing Technology 31(1):427-429.

[199] Schmidt M, Merklein M, Bourell D, Dimitrov D, Hausotte T, Wegener K, Overmeyer L, Vollertsen F, Levy GN (2017) Laser Based Additive Manufacturing in Industry and Academia. CIRPAnnals - Manufacturing Technology 66(2):561-583.

[200] Schmit J, Olszak AG, McDermed S (2002) White-Light Interferometry with Reference Signal. Proceedings of SPIE 4777:102-109.

[201] Schmitt R, Doerner D, Pfeiferb T (2006) Measurement Technology for the Machine-Integrated Determination of Form Deviations in Optical Surfaces. CIRP Annals - Manufacturing Technology 55(1):559-562. 
[202] Schnabel R, Wahl R, Klein R (2007) Efficient RANSAC for Point-cloud Shape Detection. Computer Graphics Forum 26(2):214-226.

[203] Schöch A, Salvadori A, Carmignato S, Savio E (2016) Enhancing Multisensor Data Fusion on Light Sectioning Coordinate Measuring Systems for the In-process Inspection of Freeform Shaped Parts. Precision Engineering 45:209-215.

[204] Schöch A, Salvadori A, German I, Balemi S, Bach C, Chiotti A, Carmignato S Maurizio A, Savio E (2015) High-speed Measurement of Complex Shaped Parts at Elevated Temperature by Laser Triangulation. International Journal of Automation Technology 9(5):558-566.

[205] Schwenke H, Knapp W, Haitjema H, Weckenmann A, Schmitt R, Delbressine F (2008) Geometric Error Measurement and Compensation of Machines - An Update. CIRP Annals - Manufacturing Technology 57(2):660-675.

[206] Shan XC, Kiyono S (1993) Development of a Millimeter-scale Scanning Tunneling Microscope. JSME International Journal Ser C Dynamics Control Robotics Design and Manufacturing 36(3):340-346.

[207] Shibuya A, Arai Y, Yoshikawa Y, Gao W, Nagaike Y, Nakamura Y (2010) A Spiral Scanning Probe System for Micro-aspheric Surface Profile Measurement. The International Journal of Advanced Manufacturing Technology 46(9-12):845-862

[208] Shimizu Y, Goto S, Lee JC, Ito S, Gao W, Adachi S, Omiya K, Sato H, Hisada T, Saito Y, Kubota H (2013) Fabrication of Large-size SiC Mirror with Precision Aspheric Profile for Artificial Satellite. Precision Engineering 37(3):640-649.

[209] Shinno H, Mitsui K, Tatsue Y, Tanaka N, Omino T, Tabata T (1987) A New Method for Evaluating Error Motion of Ultra Precision Spindle. CIRP Annals Manufacturing Technology 36(1):381-384.

[210] Shiraishi M (1989) Scope of In-process Measurement, Monitoring and Control Techniques in Machining Process-Part 2: In-Process Techniques for Workpieces. Precision Engineering 11(1):27-37.

[211] Shore P, Cunningham C, DeBra D, Evans C, Hough J, Gilmozzi R, Kunzmann H Morantz P, Tonnellier X (2010) Precision Engineering for Astronomy and Gravity Science. CIRP Annals - Manufacturing Technology 59(2):694-716.

[212] Sims-Waterhouse D, Piano S, Leach RK (2017) Verification of Micro-scale Photogrammetry for Smooth Three-dimensional Object. Measurement Science and Technology 28(5):055010.

[213] Stöbener D, Beekhuis B (2013) Application of an In situ Measuring System for the Compensation of Wall Thickness Variations During Turning of Thinwalled Rings. CIRP Annals - Manufacturing Technology 62(1):511-514.

[214] Stone JA, Decker JE, Gill P, Juncar P, Lewis A, Rovera GD, Viliesid M (2009) Advice from the CCL on the use of Unstabilized Lasers as Standards of Wavelength: The Helium-neon Laser at $633 \mathrm{~nm}$. Metrologia 46(1):11-18.

[215] Su P, Parks RE, Wang L, Angel RP, Burge JH (2010) Software Configurable Optical Test System: A Computerized Reverse Hartmann Test. Applied Optics 49(23):4404-4412.

[216] Su P, Wang Y, Oh CJ, Parks RE, Burge JH (2011) Swing Arm Optical CMM: Self Calibration with Dual Probe Shear Test. Proceedings of SPIE 8126. 81260W.

[217] Suh SH, Lee ES, Kim HC, Cho JH (2002) Geometric Error Measurement of Spira Bevel Gears using a Virtual Gear Model for STEP-NC. International Journal of Machine Tools and Manufacture 42(3):335-342.

[218] Suzuki H, Onishi T, Moriwaki T, Fukuta M, Sugawara J (2008) Development of a $45^{\circ}$ Tilted On-machine Measuring System for Small Optical Parts. CIRP Annals - Manufacturing Technology 57(1):411-414.

[219] TakahashiS, Miyoshi T, Takaya Y, Saito K (1998) In-process Measurement Method for Detection and Discrimination of Silicon Wafer Surface Defects by Laser Scattered Defect Pattern. CIRPAnnals - Manufacturing Technology 47(1):459-462.

[220] Takaya Y (2014) In-process and On-machine Measurement of Machining Accuracy for Process and Product Quality Management: A Review. International Journal of Automation Technology 8(1):4-19.

[221] Takaya Y, Maruno K, Michihata M, Mizutani Y (2016) Measurement of a Too Wear Profile using Confocal Fluorescence Microscopy of the Cutting Fluid Layer. CIRP Annals - Manufacturing Technology 65(1):467-470.

[222] Takeda M (1990) Spatial-carrier fringe-pattern analysis and its applications to precision interferometry and profilometry: An overview. Industrial Metrology 1(2):79-99.

[223] Tanaka H, Tazawa K, Sato H, O-hmori M, Sekiguchi H, Taniguchi N (1981) Application of a New Straightness Measurement Method to Large Machine Tool. CIRP Annals - Manufacturing Technology 30(1):455-459.

[224] Tian X, Deng H, Fujishima M, Yamazaki K (2007) Quick 3D Modeling of Machining Environment by Means of On-machine Stereo Vision with Digital Decomposition. CIRP Annals - Manufacturing Technology 56(1):411-414.

[225] Thomas M, Beauchamp Y (2003) Statistical Investigation of Modal Parameters of Cutting Tools in Dry Turning. International Journal of Machine Tools and Manufacture 43(11):1093-1106.

[226] Tosello G, Haitjema H, Leach RK, Quagliotti D, Gasparin S, Hansen HN (2016) An International Comparison of Surface Texture Parameters Quantification on Polymer Artefacts using Optical Instruments. CIRP Annals - Manufacturing Technology 65(1):529-532.

[227] Toshiba Machine Co., Ltd (2018) Catalogue. On-machine probe

[228] TRIOPTICS GmbH (2018) Catalogue. $\mu$ Phase $^{\overline{\mathbb{R}}}$ 500/1000,

[229] Uda Y, Kohno T, Yazawa T (1994) In-process Measurement and Workpiecereferred form Accuracy Control. Journal of JSPE 60(8):1159-1163.

[230] Uekita M, Takaya Y (2016) On-machine Dimensional Measurement of Large Parts by Compensating for Volumetric Errors of Machine Tools. Precision Engineering 43:200-210.

[231] Vorburger TV, Teague EC (1981) Optical techniques for on-line measurement of surface topography. Precision Engineering 3(2):61-83.

[232] Walecki WJ, Szondy F, Hilali M (2008) Fast In-line Surface Topography Metrology Enabling Stress Calculation for Solar Cell Manufacturing for throughput in Excess of 2000 Wafers Per Hour. Measurement Science and Technology 19(2):025302.

[233] Wan X, Hua L, Wang XF, Peng QZ, Qin XP (2011) An Error Control Approach to Tool Path Adjustment Conforming to the Deformation of Thin-walled Workpiece. International Journal of Machine Tools and Manufacture 51(3):221-229.
[234] Wang WB, Wu BW, Liu PF, Huo D, Tan JB (2017) Absolute surface metrology by shear rotation with position error correction. Journal of the European Optical Society-Rapid Publications 13(1):2-6.

[235] Weckenmann A, Estler T, Peggs G, McMurtry D (2004) Probing Systems in Dimensional Metrology. CIRPAnnals - Manufacturing Technology 53(2):657-684.

[236] Weckenmann A, Hoffmann J (2007) Long Range 3D Scanning Tunneling Microscopy. CIRP Annals - Manufacturing Technology 56(1):525-528.

[237] Weckenmann A, Jiang X, Smmer KD, Neuschaefer-Rube U, Seewig J, Shaw L, Estler T (2009) Multisensor Data Fusion in Dimensional Metrology. CIRP Annals - Manufacturing Technology 58(2):701-721.

[238] Weichert C, Bosse H, Flügge J, Köning R, Köchert P, Wiegmann A, Kunzmann H (2016) Implementation of Straightness Measurements at the Nanometer Comparator. CIRP Annals - Manufacturing Technology 65(1):507-510.

[239] Whitehouse DJ (1976) Some Theoretical Aspects of Error Separation Techniques in Surface Metrology. Journal of Physics E: Scientific Instruments 9 (7):531-536.

[240] Whitehouse DJ (1988) Comparison Between Stylus and Optical Methods for Measuring Surfaces. CIRP Annals Manufacturing Technology 37(2):649-653.

[241] Whitehouse DJ (2011) Handbook of Surface and Nanometrology, 2nd edn. CRC Press, Boca Raton.

[242] Woodward S, Brown S, Dury M, Mccarthy M (2016) Traceable In-process Measurement (TIM) - Producing Dimensional Transfer Artefacts for the Assessment of Workshop Machine Tool Performance. Proceedings of the 16th International Conference of Euspen, 1-2.

[243] Wyant JC (2002) Advances in Interferometric Metrology. Proceedings of SPIE 4927:154-162.

[244] Xi JP, Zhao HY, Li B, Ren DX (2016) Profile Error Compensation in Crossgrinding Mode for Large-diameter Aspheric Mirrors. International Journal of Advanced Manufacturing Technology 83(9-12):1515-1523.

[245] Xu B, Shimizu Y, Takeishi T, Ito S, Gao W (2012) Surface form Measurement and Analysis of a Cylindrical Workpiece with Microstructures. Journal of Advanced Mechanical Design Systems and Manufacturing 6(6):936-948.

[246] Xu B, Shimizu Y, Ito S, Gao W (2013) Surface Profile Measurement of Internal Micro-structures. International Journal of Precision Engineering and Manufacturing 14(9):1535-1541.

[247] Xu B, Shimizu Y, Ito S, Gao W (2015) Pitch Deviation Measurement of an Involute Spur Gear by a Rotary Profiling System. Precision Engineering 39:152160.

[248] Yamaguchi I, Liu J, Kato J (1996) Active Phase-shifting Interferometers for Shape and Deformation Measurements. Optical Engineering 35(10):29302937.

[249] Yamauchi M, Hibino K (2003) Measurement of Air Turbulence for Onmachine Interferometry. Applied Optics 42(34):6869-6876.

[250] Yang SM, Zhang GF (2018) A Review on Interferometry for Geometric Measurement. Measurement Science and Technology 29(10):102001.

[251] Yang SM, Jiang X, Maxwell G, Wyatt R, Rogers D (2010) A Chip Tuneable Lase Developed for On-line Micro-nano Scale Surface Measurements. Measurement Science and Technology 21(10):105901.

[252] Yang SM, Yang LL, Zhang GF, Wang T, Yang XK (2018) Modeling and Calibration of the Galvanometric Laser Scanning Three-dimensional Measurement System. Nanomanufacturing and Metrology 1(3):180-192.

[253] Yan JW, Baba H, Kunieda Y, Yoshihara N, Kuriyagawa T (2007) Nano Precision On-machine Profiling of Curved Diamond Cutting Tools using a White-light Interferometer. International Journal of Surface Science and Engineering 1 (4):441-455

[254] Yoshino T, Nara M, Mnatzakanian S, Lee BS, Strand TC (1987) Laser Diode Feedback Interferometer for Stabilization and Displacement Measurements. Applied Optics 26(5):892-897.

[255] Zhang B, Ziegert J, Farahi F, Davies A (2016) In situ Surface Topography of Laser Powder Bed Fusion using Fringe Projection. Additive Manufacturing 12:100-107.

[256] Zhang GX, Wang RK (1993) Four-Point Method of Roundness and Spindle Error Measurements. CIRP Annals - Manufacturing Technology 42(1):593-596.

[257] Zhang XD, Jiang LL, Zeng Z, Fang FZ, Liu X (2015) High Angular Accuracy Manufacture Method of Micro V-grooves Based on Tool Alignment by on Machine Measurement. Optics Express 23(21):27819-27828.

[258] Zhang XD, Jiang LL, Zhang GZ (2017) Novel Method of Positioning Optical Freeform Surfaces Based on Fringe Deflectometry. CIRP Annals - Manufacturing Technology 66(1):507-510.

[259] Zhang XD, Zeng Z, Liu XL, Fang FZ (2015) Compensation Strategy for Machining Optical Freeform Surfaces by the Combined On- and Off-machine Measurement. Optics Express 23(19):24800-24810.

[260] Zhang XQ Tnay GL, Liu K, Kumar AS (2018) Effect of Apex Offset Inconsistency on Hole Straightness Deviation in Deep Hole Gun Drilling of Inconel 718. International Journal of Machine Tools and Manufacture 125:123-132.

[261] Zhang Y, Zhang DH, Wu BH (2015) An Adaptive Approach to Error Compensation by On-machine Measurement for Precision Machining of Thin-walled Blade. Proceedings of IEEE International Conference on Advanced Intelligent Mechatronics, 1356-1360.

[262] Zhao Y, Brown RJ, Kramer TR, Xu X (2011) Information Modeling for Interoperable Dimensional Metrology, Springer

[263] Zhu A, He D, Zhao J, Wu H (2017) Online Tool Wear Condition Monitoring using Binocular Vision. Insight: Non-Destructive Testing and Condition Monitoring 59(4):203-210.

[264] Zatarain M, Mendikute A, Inziarte I (2012) Raw Part Characterisation and Automated Alignment by Means of a Photogrammetric Approach. CIRP Annals-Manufacturing Technology 61(1):383-386.

[265] Zobrist TL, Burge JH, Martin HM (2010) Accuracy of Laser Tracker Measurements of the GMT 8.4 m Off-axis Mirror Segments. Proceedings of SPIE 7739. 77390S

[266] Zygo Corporation (2018) Catalogue. Interferometer System - Verifire ${ }^{T M} X L$, . 